\title{
Sakarya Zonunun Güney Kesiminde Yüzeylenen Geç Kretase Alkalen Volkanitlerinin Jeokimyasal Özelliklerinin Karşılaştırılması
}

\author{
Comparison of the Geochemical Characteristics of Late Cretaceous Alkalen Volcanic Rocks \\ from the Southern Border of Sakarya Zone
}

\author{
Cüneyt ŞEN ${ }^{1, a}$, Emre AYDINÇAKIR*2,b ${ }^{2, b}$ fuk Celal YAĞCIOĞLU ${ }^{1, c}$, Tülay BAK ${ }^{1, d}$ \\ ${ }^{I}$ Karadeniz Teknik Üniversitesi, Mühendislik Fakültesi, Jeoloji Mühendisliği Bölümü, 61080, Trabzon \\ ${ }^{2}$ Gümüşhane Üniversitesi, Mühendislik ve Doğa Bilimleri Fakültesi, Jeoloji Mühendisliği Bölümü, 29100, Gümüşhane
}

• Geliş tarihi / Received: 01.03.2018 • • Düzeltilerek geliş tarihi / Received in revised form: 15.05.2018 • Kabul tarihi / Accepted: 22.05 .2018

\begin{abstract}
$\ddot{O} z$
Sakarya Zonunun güney kesiminde Bayburt, Amasya-Gümüşhacıköy ve Ankara-Kalecik lokasyonlarında Üst Kretase'nin son dönemlerinde benzer stratigrafik seviyelerde yüzeylenen alkalen volkanitler makroskobik olarak iri analsimleşmiş lösit porfirleri ve iri piroksen porfirleri içeren iki farklı litoloji sunarlar. Bu kayaçlar çarpışma öncesi yaşlı okyanus kabuğunun yitim açısının dikleşmesi sonucu, metasomatizmaya uğramış flogopitce zengin manto kayaçlarının düşük dereceli kısmi ergimesi sonucu oluşan kaynak magmalardan itibaren oluşmuşlardır. Oluşumlarını izleyen süreçte alkalen magma, kabuk içerisindeki orta/sı̆̆ derinliklerdeki magma odalarında diferansiyasyona uğrayarak, iki farklı litolojide yeryüzüne ulaşmıştır.
\end{abstract}

Anahtar kelimeler: Alkalen volkanizma, Analsimleşmiş lösit, Sakarya Zonu, Üst Kretase

\begin{abstract}
Alkaline volcanics exposed at similar stratigraphic levels in Upper Cretaceous at Bayburt, Amasya-Gümüşhaclköy and Ankara-Kalecik locations along the southern boundary of the Sakarya Zone provide macroscopically two different lithologies which are containing large pyroxene porphyries and large analcimized leucite porphyries. These rocks formed as a result of the low-grade partial melting of the metasomatized phlogopite-rich mantle rocks, which resulted in the step subduction angle of the aged oceanic crust before the collision. In the course of following their cases, in the middle / shallow depths of the crust, in the magma chambers they underwent differentiation and reached two different lithologies.
\end{abstract}

Keywords: Alkaline volcanism, Analcimized leucite, Sakarya Zone, Upper Cretaceous

\footnotetext{
*b Emre AYDINÇAKIR; aydincakir61@gmail.com; Tel: (0456) 2331000 (dâhili: 1706); orcid.org/0000-0001-8704-8485

${ }^{a}$ orcid.org/0000-0002-2873-073X $\quad{ }^{\circ}$ orcid.org/0000-0001-7158-9017 $\quad$ orcid.org/0000-0002-8845-3877
} 


\section{Giriş}

Şengör ve Y1lmaz (1981) ile Okay ve Tüysüz (1999) Anadolu'nun kuzeyinde yer alan ve Ege Denizi'nden başlayarak Küçük Kafkaslar'a kadar uzanan tektonik zonu "Sakarya Zonu" olarak adlandırmıştır. Sakarya Zonu, Paleozoyik ve Mesozoyik dönemlerde aktif yitim ve Senozoyik dönemde çarpışma sonucu oluşmuş magmatik aktiviteler ile bunlara eşlik eden tortulaşma ve başkalaşım olayları sonucu vücut bulmuştur. Karmaşık plütonik, volkanik, metamorfik ve sedimanter kayaç oluşumlarına tektonik hareketler sonucu gelişmiş kırıklar, kıvrımlar ve sonrasında gelişen fiziksel ve kimyasal ayrışmalar eşlik ettiğinden, Sakarya Zonu'nun oluşumunu anlamak kolay olmamıştır. Bölgedeki jeolojik problemlerin çözümü için ayrıntılı çalışmalar yapılması gerekmektedir.

$\mathrm{Bu}$ çalışma, Türkiye'nin tektonik birliklerinden Sakarya Zonu'nun (Şekil 1) güney kesiminde, Ankara-Kalecik (Üşenmez, 1973; Ataman vd., 1976; Gülmez ve Genç, 2015) AmasyaGümüşhacıköy (Gülmez vd., 2016), AmasyaMerkez (Alp, 1972; Eyüboğlu, 2010; Eyüboğlu vd., 2011), Çorum-Mecitözü (Erk ve Seymen, 1993), Tokat-Reşadiye (Seymen, 1975); BayburtEverekhanları (Bektaş ve Gedik, 1988; Altherr vd., 2008) ve Erzurum-İspir (Eyüboğlu, kişisel görüşme), benzer stratigrafik düzeylerde (Üst Kretase'nin son dönemleri) yüzeylenme veren alkali volkanitlerin jeokimyasal, petrografikmineralojik özelliklerinin karşılaştırılmasını amaçlamaktadır.

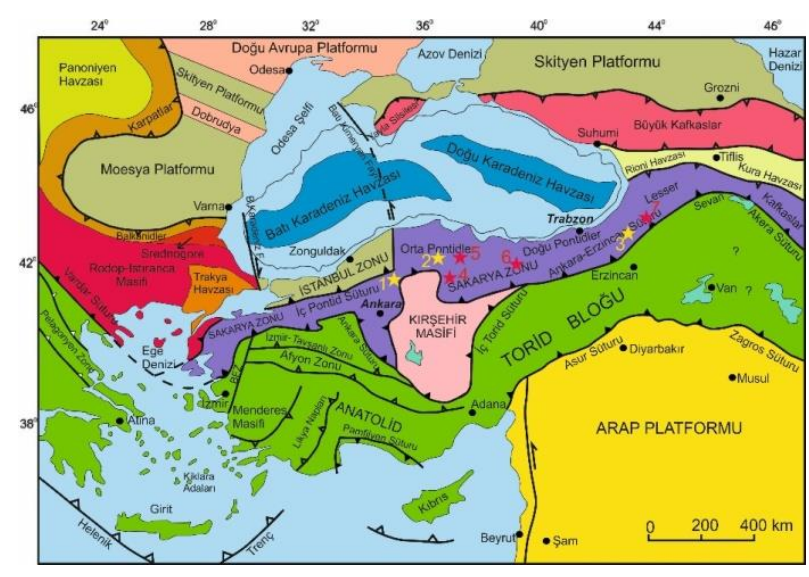

Şekil 1. İnceleme alanları (sarı yıldızlar, 1-AnkaraKalecik, 2-Amasya Gümüşhacıköy, 3-BayburtEverekhanlar) ve stratigrafik olarak benzer oluşumların (4-Çorum-Meçitözü, 5-Amasya Merkez, 6-TokatReşadiye ve 7-Erzurum-İspir) Türkiye Tektonik Birlikleri'nden (Okay ve Tüysüz, 1999) Sakarya Zonu içerisindeki konumları.

\section{Bölgesel Stratigrafi ve İncelenen volkanitlerin konumu}

Benzer stratigrafik seviyede bulunan alkalen volkanitler Ankara-Kalecik (Orta Pontid'lerde), Amasya-Gümüşhacıköy (Orta-Doğu Pontid geçişinde) ve Bayburt-Everekhanları (Doğu Pontidler'de) yüzeylenir.

Orta Pontidler'de temel kayaçları Orta Silüryen kırıntıları üzerine gelen Permo-Karbonifer kireçtaşları oluştururken, Doğu Pontidler'de ise temel kayaçları Erken Karbonifer yaşlı metamorfitler ve bunları keserek yerleşen OrtaGeç Karbonifer yaşlı granitoyidler oluşturur (Alp, 1972; Yılmaz, 1973; Çoğulu, 1975; Topuz vd., 2010; Dokuz, 2011; Karsl1 vd., 2016; Kaygusuz vd., 2012, 2016; Dokuz vd., 2017a). Bu temel üzerine uyumsuz olarak gelen Jura yaşlı kayaçlar, Orta Pontid'lerde, yer yer Permiyen kireçtaş1 blokları içeren kırıntılılardan oluşmaktadır (Alp, 1972).

Doğu Pontid'ler de ise birbirleriyle yanal geçiş gösteren ve kısa mesafelerde kalınlık farkları sunan epiklastik kayaçlarla birlikte andezit, diyabaz, bazalt, aglomera, tüf ve tüffitler bulunur. (Şen, 2007; Y1lmaz ve Kandemir, 2003; Kandemir, 2004; Kandemir ve Y1lmaz, 2009; Dokuz vd., 2017b; Karslı vd., 2017). Neredeyse, tüm Pontid'ler boyunca Erken-Orta Jura çökellerinin birikiminden sonra, Malm'den itibaren, Alt Kretase sonuna kadar süren dönemde, sakin tektonik koşulların kontrolünde karbonat platformu (neritik ve mikritik kireçtaşları) oluşmuştur (Alp, 1972; Yılmaz, 2002). Üst Kretase dönemi, Pontid'lerde litolojik ve jeolojik olaylar bakımından en karmaşık dönemdir (Okay ve Şahintürk, 1997; Kaygusuz ve Aydınçakır, 2011; Kaygusuz vd., 2011; Aydınçakır, 2016). Çalışma alanlarının yer aldığg Pontid'lerin güney sinırları (Ankara - Kalecik; Amasya-Gümüşhacıköy, Bayburt) dikkate alındığında, Üst Kretase dönemi, ofiyolitik melanj oluşumları (Alp, 1972; Bektaş ve Gedik, 1988, Eyüboğlu, 2010, Eyüboğlu vd.; 2011) ve bunları uyumsuz olarak üzerleyen yerel volkanitler ve piroklastitleri ile kumtaşı, silttaşı, marn ve kireçtaşı çökelimleri ile temsil edilir. $\mathrm{Bu}$ çalışmada incelenen volkanitler de bu stratigrafik seviyede bulunmaktadır. Hem Orta hem de Doğu Pontid'lerdeki çalışma bölgelerinde, Üst Kretase kayaçları, Eosen yaşlı tortul, volkanit katkılı volkano-tortul birimler tarafindan örtülmüştür (Okay vd., 1997; Aydın vd. 2008; Aydınçakır ve Şen, 2013; Aydınçakır, 2016; Yücel vd., 2017). 


\section{Analitik Yöntemler}

Bayburt-Everekhanlar1, Amasya-Gümüşhacıköy ve Ankara-Kalecik lokasyonlarında volkanik kayaçların petrokimyasal karakteristiklerini belirleyebilmek için yaklaşık yüz adet kayaç örneği derlenmiştir. Petrografik çalışmalar için Karadeniz Teknik Üniversitesi, Mühendislik Fakültesi, Jeoloji Mühendisliği Bölümü, İnce Kesit Laboratuvarı'nda ince kesitleri hazırlanan örnekler, bölümün Araştırma Mikroskop Laboratuvarı'nda polarizan mikroskop altında incelenerek dokusal ve mineralojik tayinleri yapılmıştır.

Petrografik çalışmalar sırasında taze (veya az ayrışmış) örnekler seçilerek, Örnek Hazırlama Laboratuvarlarında kimyasal analizler için hazırlanmıştır. Bu örnekler önce çeneli kırıcılarda 1-2 cm boyutlarına indirilmiş, daha sonra tungsten-karbidten yapılmış halkalı ögütücülerde yaklaşık -180 mesh boyutuna kadar öğütülmüştür. 31 adet örnek plastik poşetlerde saklanarak kimyasal ana ve iz element analizleri için Acme Analiz Laboratuvarı'na (Vancouver, Kanada) gönderilmiştir. Ana ve iz elementler ICP (Inductively Coupled Plasma), nadir toprak elementler ise ICP-MS (Inductively Coubled Plasma-Mass Spectrometry) aletleri kullanılarak analizler yapılmıştır. Öğütülen toz örneklerden 0.2 gr alınarak 1.5 gr $\mathrm{LiBO}_{2}$ ile karıştırılarak, \% 5 $\mathrm{HNO}_{3}$ içeren bir sıvı içinde çözündürülmüştür. Analiz yapılan alete standartlar (STD SO 18) girildikten sonra örnekler analiz edilmiştir. Ana elementler yüzde ağırlık, iz elementler ise ppm olarak ölçülmüştür. Nadir toprak elementler ise, toz örneklerden $0.25 \mathrm{gr}$ alınarak dört farklı asit içerisinde çözündürülmüş ve analiz sonuçları ppm olarak tespit edilmiştir.

\section{Bulgular}

\subsection{Arazi İlişkileri}

Bu çalışmada Sakarya kıtasının (Şekil 1), güney sinirı boyunca Ankara Kalecik'ten Erzurum İspir'e kadar uzanan bir hat üzerinde yer alan ve hemen hem benzer stratigrafik seviyelerde bulunan (Şekil 2) alkalen volkanizmanın iyi gözlendiği üç lokasyon, doğudan batıya, Bayburt Everekhanları, Amasya Gümüşhacıköy - İmirler ve Ankara Kalecik - Tilkiköy lokasyonları çalışılmıştır.

\subsection{Bayburt-Everekhanları Yöresi}

Çalışma konusu kayaçlar, Bayburt-Erzurum karayolu üzerinde, Bayburt'un Maden Beldesinin $5 \mathrm{~km}$ güneyinde yaklaşı $1.5 \mathrm{~km}^{2}$ lik bir alanda yüzeylenmektedir (Şekil 3). Bölgede ilk ayrıntılı jeolojik çalışmayı yapan Bektaş ve Gedik (1988) seriyi Everekhanları Formasyonu olarak adlandırmıştır. Everekhanları Formasyonuna ait kayaçlar daha sonra ayrint1lı olarak Altherr vd. (2008) tarafından çalışılmıştır.

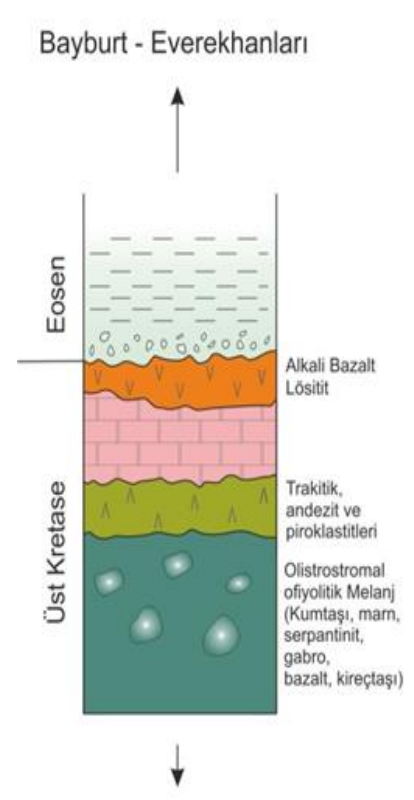

Bektaş ve Gedik (1988)'den basitleştirilerek
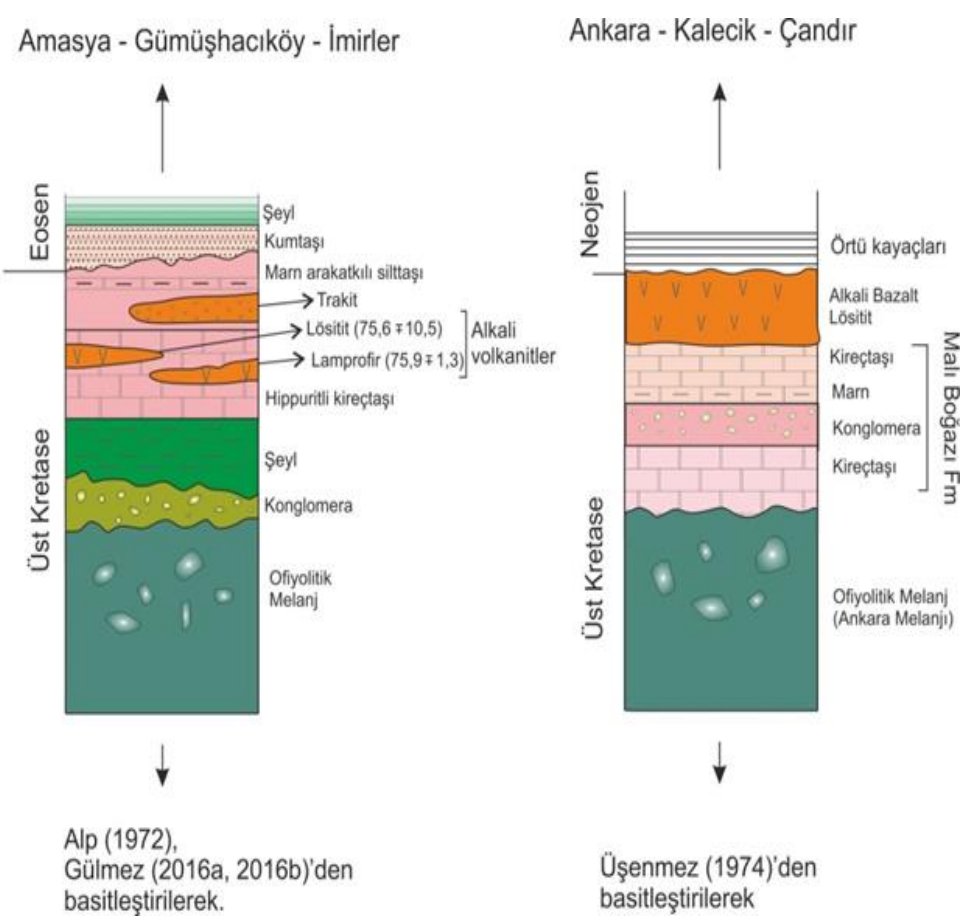

Ankara - Kalecik - Çandır basitleştirilerek

Şekil 2. İnceleme alanlarında buluna alkalen karakterli volkanitlerin stratigrafik konumu. 
Formasyon, Üst Kretase yaşlı kalın tabakalı rudistli resifal kireçtaşlarının düzensiz aşınma yüzeyinin üzerine çökelmiştir. Birim, alttaki kireçtaşlarının oluşturduğu kırmızı renkli konglomeratik bir seviye ile başlar.

Konglomeratik seviye üzerine, ojit kristallerinin gözle seçilebildiği gri renkli matrikse sahip volkanit ile volkanoklastik seviyeler ardalanmal olarak gelmektedir. İri analsim kristalleri içeren grimsi-kahverengi matrikse sahip volkanitler ise serinin en üst seviyelerindeki breşik (Şekil 4) ve akma yapılarını oluşturur. Bektaş ve Gedik (1988) formasyonun genel özellikleri itibariyle karasal volkano-tortul bir istif niteliğinde, toplam kalınlığının da yaklaşık $300 \mathrm{~m}$ civarında olduğunu belirtmiştir. Araştırmacılar formasyonun yaşını Paleosen olarak verirken, benzer bir şekilde Altherr vd. (2008) Everekhanları Formasyonunun yaşının alttan Üst Kampaniyen-Maastristiyen (Özer ve Fenerci, 1993; Fenerci, 1994; Y1lmaz vd., 2003) yaşlı rudistli kireçtaşları ile üstten nummulit içeren Üst Pleosen-Yipresiyen yaşl1 flişik, konglomera, kumtaşı ve şeyllerden oluşan birim (Okay vd., 1997) ile sınırlandığını belirtmiştir.

\subsection{Amasya-Gümüş̧hacıköy-Imirler Yöresi}

Birim, Amasya-Gümüşhacıköy ve civarında yer yer dayklar, yer yer de küçük alanda akma yapısı göstererek yüzeylenir. Arazi çalışmaları AmasyaGümüşhacıköy'ün yaklaşık $3 \mathrm{~km}$ batısında bulunan İmirler Köyü’nde bulunan göletin memba tarafında yapılmış ve çalışma alanının jeoloji haritası Şekil 5'de verilmiştir. Çalışılan volkanitler, Alp (1972)'nin Lokman Formasyonu olarak adlandırdığı birimin bir parçasıdır. Lokman Formasyonu tabanda ofıyolitik melanjla başlar ve bu seviye üzerine trakiandezit ve piroklastitleri gelir. Formasyonun üst seviyelerinde şeyller ve bunların üzerine uyumlu gelen rudistli resifal kireçtaşları bulunur. İncelenen volkanitler, söz konusu şeyller ile kireçtaşlarını keserek yerleşmiştir (Şekil 6). Alp (1972) çalıştı̆̆ Amasya bölgesinde volanizmanın bataklık çökelleriyle ardalandığını belirtmesine karşın, incelenen alanda, sadece şeyllere ve bunlarla uyumlu kireçtaşlarına rastlanmıştır. Volkanitlerin de içerisinde bulunduğu, Lokman Formasyonu, Eosen yaşlı kumtaş1, siltaşı, marn ve kireçtaşı ardalanmasından oluşan fliş tarafindan uyumsuz olarak örtülür (Tüysüz, 1996).

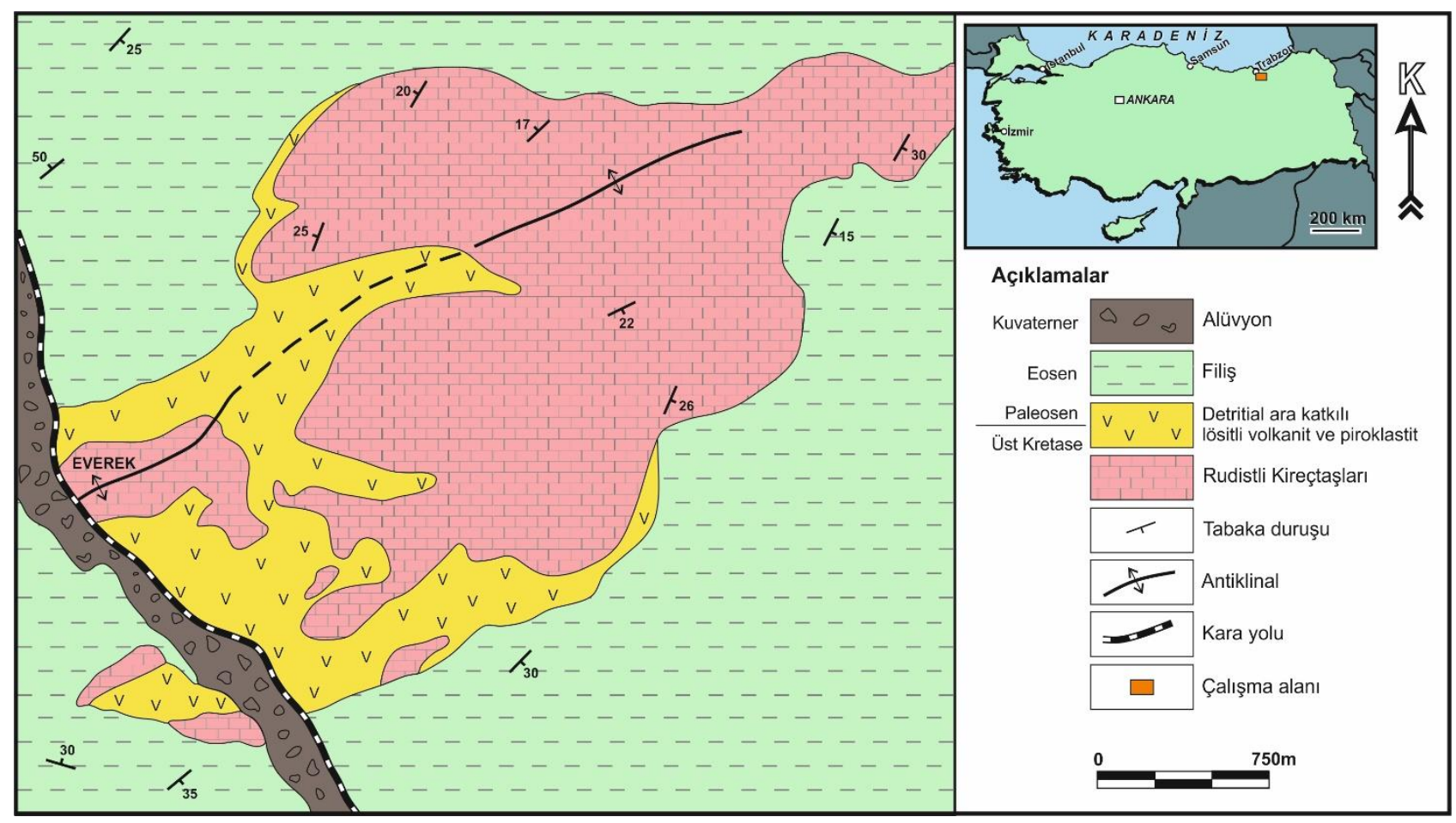

Şekil 3. Bayburt-Everekhanları ve civarının jeoloji haritası (Bektaş ve Gedik, 1988'den alınmıştır). 

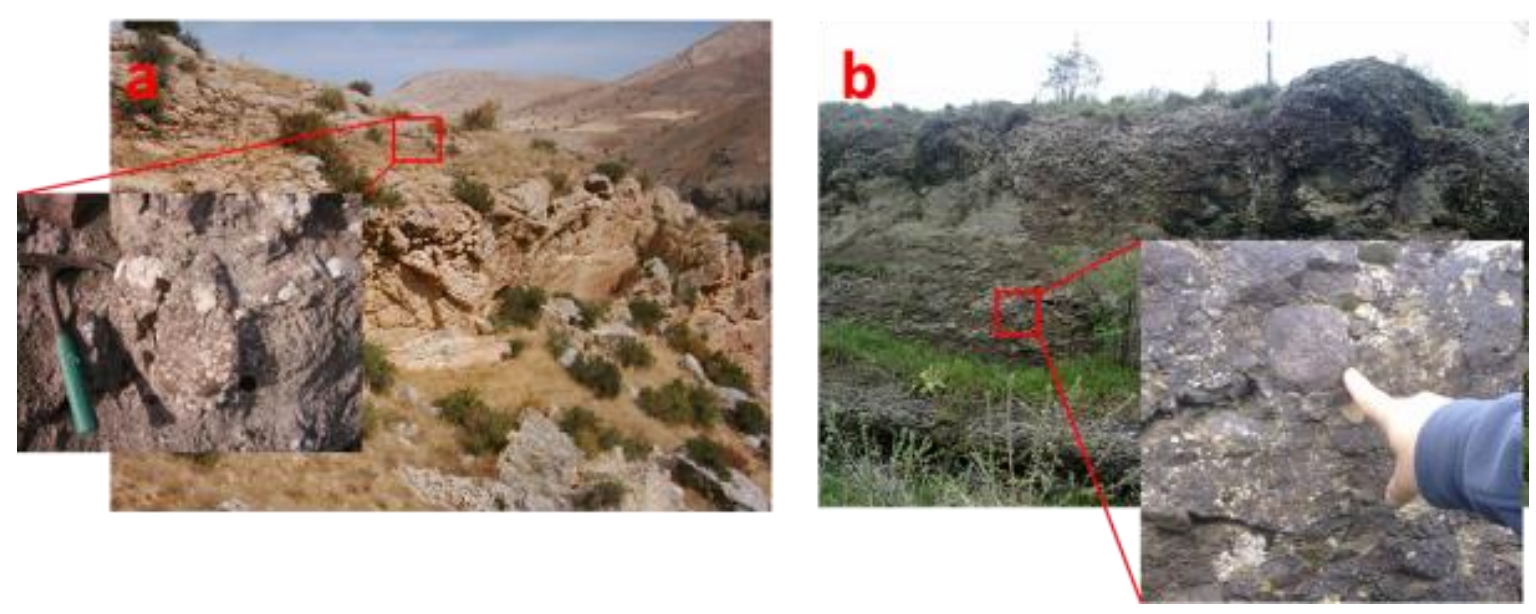

Şekil 4. Analsimleşmiş lösit içeren köşeli-yarı köşeli bloklardan oluşmuş aglomeramsı-breşler (a). Everekhanları Formasyonu üzerine uyumsuz olarak gelen Eosen Flişinin taban seviyelerinde bulunan konglomeralar içerisindeki analsimleşmiş lösit içeren volkanit çakılı (b).

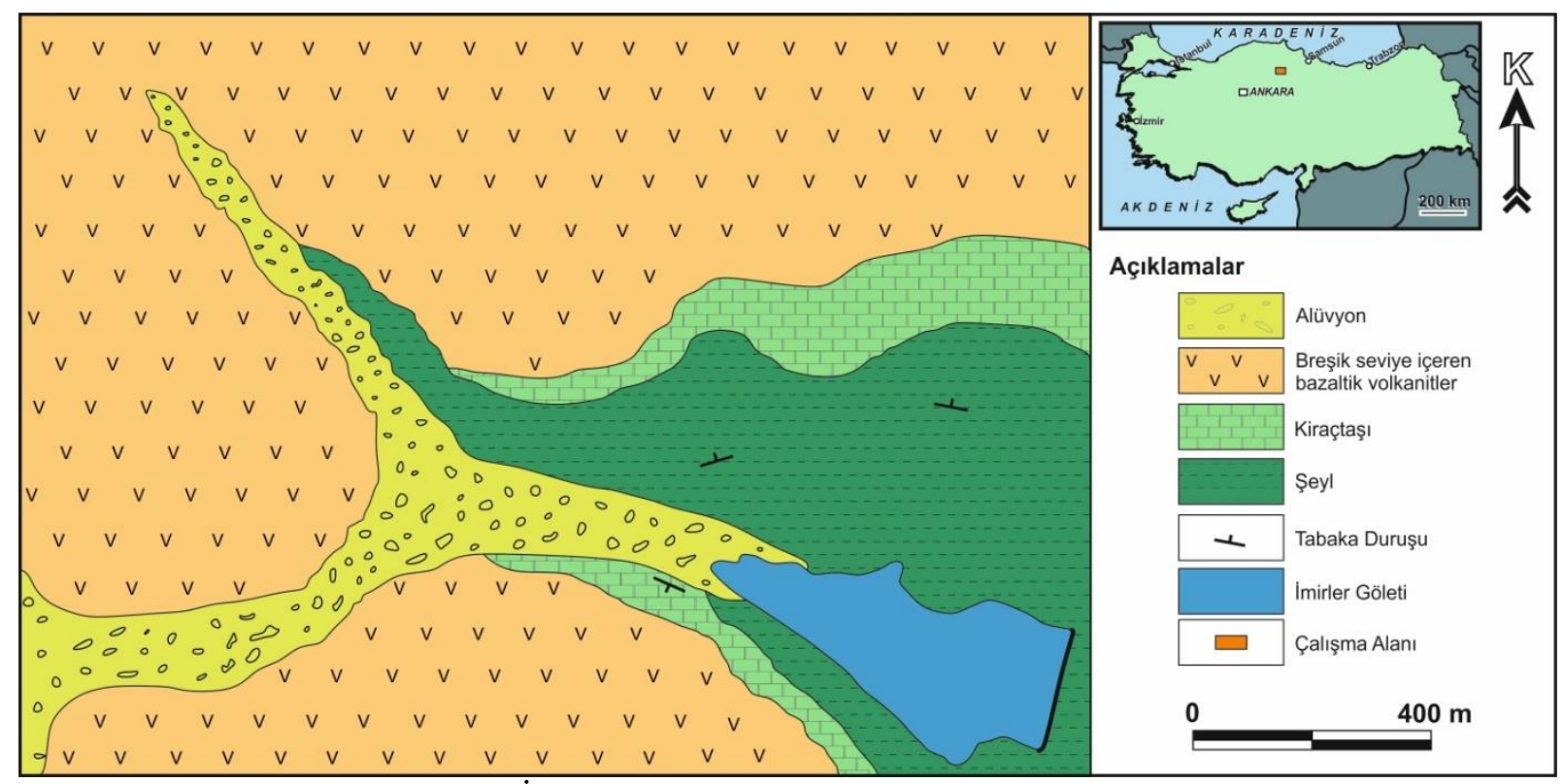

Şekil 5. Amasya Gümüşhacıköy İmirler Köyü ve civarında yüzeylenen alkalen volkanitleri gösteren jeoloji haritas1.

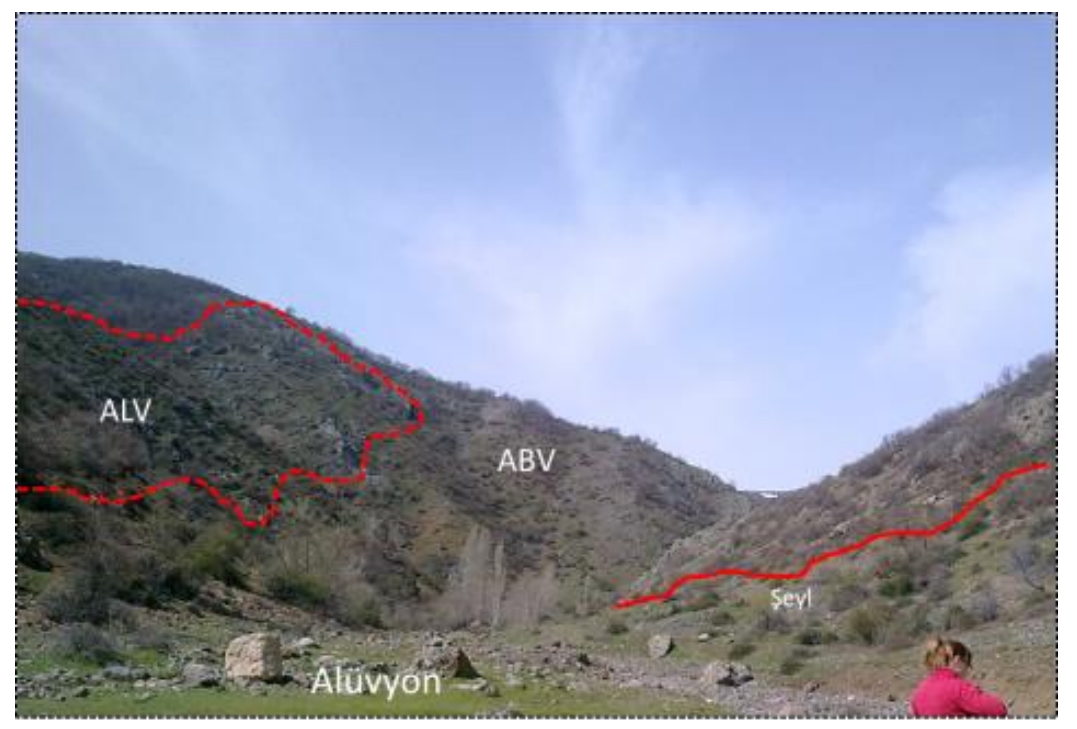

Şekil 6. Amasya-

Gümüşhacıköy-İmirler Köyü Göletinin memba tarafinda şeyller üzerine akmış olarak görülen volkanitler.

Analsimleşmiş lösit içeren volkanitler (kırmızı kesikli çizgi ile belirlenen alan) alkalen volkanitler içerisinde sınırlı alanlarda kafalar şeklinde gözlenir. 


\subsection{Ankara-Kalecik-Tilkiköy}

Alkalen volkanizmanın ürünlerine AnkaraKalecik civarında geniş alanlarda dayk ve küçük lav akmaları şeklinde rastlanır. Bu çalışmada incelenen volkanitler, Kalecik İlçe merkezinin yaklaşık $20 \mathrm{~km}$ kuzeyinde Tilkiköy-Gökçeören köyleri ile Kızılırmak arasında bulunan alanda yüzeylenirler (Şekil 7).

Üşenmez (1973) tarafindan bölgede gerçekleştirilen ilk ayrıntılı çalışmaya göre temeli bazaltik, gabroyik ve serpantinleşmiş kütlelerle beraber bulunan kireçtaşı bloklarından oluşan Ankara Melanjı oluşturur. Kireçtaşı blokları içeren diyabaz ve volkanik breşler bu seri üzerine uyumlu olarak gelir. Malı Boğazı Kalkerleri tabanda konglomeratik bir seviye ile başlayıp, kalkerli kırıntılı seviyelerle kireçtaşlarına geçiş gösterir. Alkalen volkanitler ise söz konusu kireçtaşlarını keserekyerleşmiştir.

Çapan (1984), Malı Boğazı Formasyonunun oluşumunun Senomaniyen'den Maestrichtiyen'e kadar devam ettiğini, Formasyonun üzerinde bulunan alkali bazaltlardan alınan klinopiroksen ve biyotit minerallerinin $\mathrm{K}$-Ar yaşlarının 60-65 milyon y1l (Daniyen) olduğunu belirtmiştir. Tüm bu birimler, Geç Neojen serileri tarafindan örtülmüştür (Şekil 8).

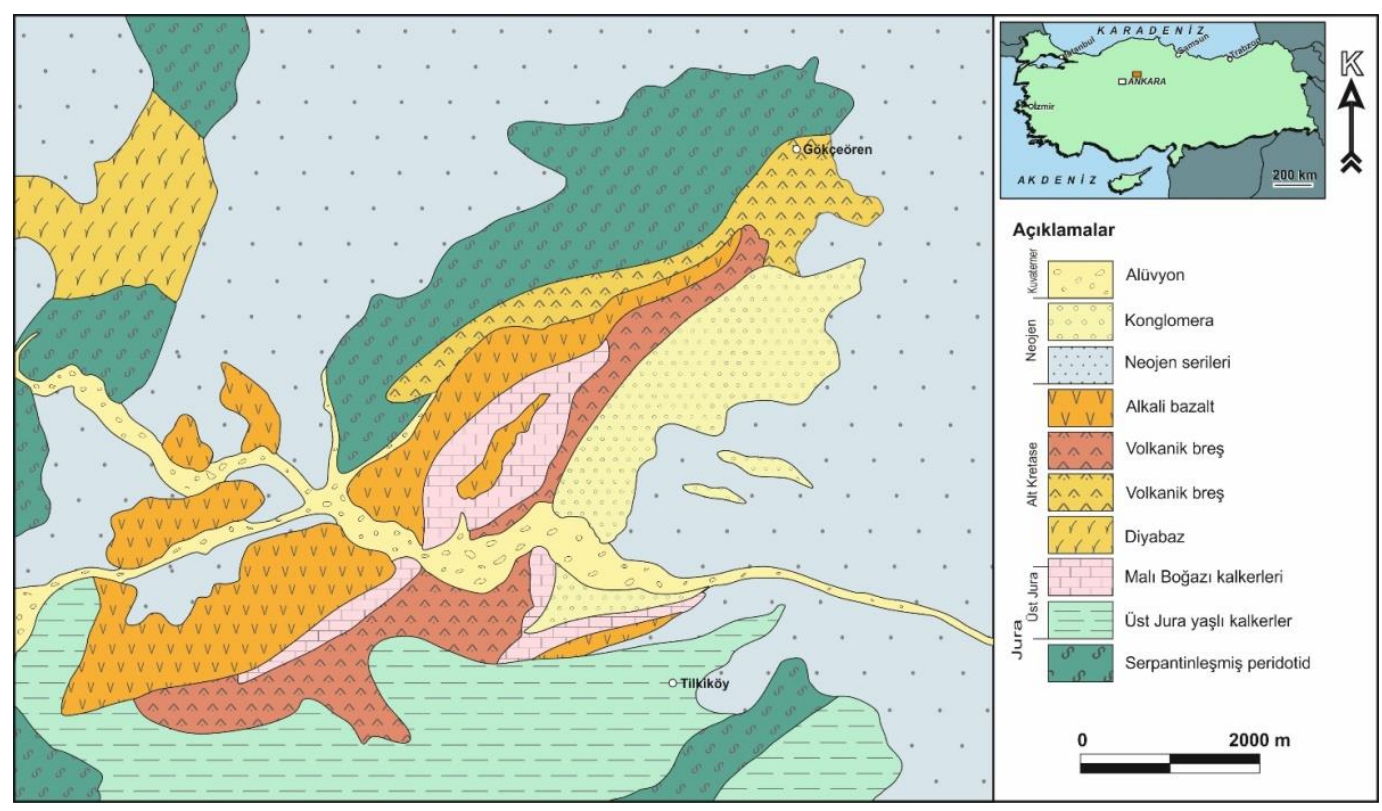

Şekil 7. Ankara-Kalecik Tilkiköy-Gökçeören Köyleri ve civarının jeoloji haritası (Üşümez, 1973'den basitleştirilerek alınmıştır).
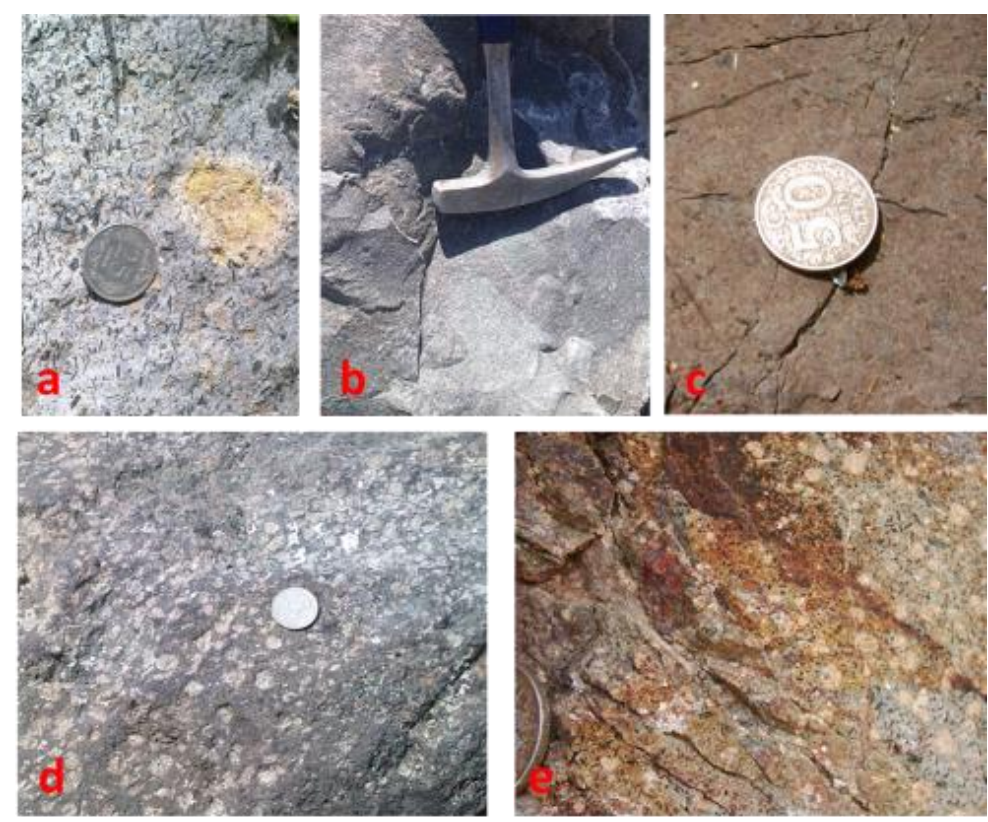

- Şekil 8. Yeşil renkli, öz ve yarı öz şekilli piroksen kristalleri içeren alkali bazaltik volkanitler (ABV; a, Gümüşhacıköy; b, Kalecik ve c, Bayburt). İri beyazıms1-pembemsi analsimleşmiş lösit içeren volkanitler (ALV; d,Gümüşhacıköy ve e,Bayburt). 


\subsection{Jeokimya}

Her üç lokasyonda da, makroskobik olarak iki farklı tür volkanik kayaç tanımlanmıştır. Yaygın olarak görülen kayaçlar koyu gri, gri renklidir ve makroskopik olarak koyu yeşil renkli piroksen kristalleri içeren alkali bazaltik volkanitlerdir (ABV, Şekil 8a, b ve c). Beyazımsı-pembemsi iri analsimleşmiş lösit içeren volkanitler ise grimsikahverengimsi matrikse sahiptir (ALV, Şekil 8d ve e) ve alkali bazaltik volkanitlere göre arazide daha sinırlı alanlarda yayılım gösterirler.

Arazi çalışmaları sırasında derlenen örneklerden itibaren 31 örneğin (Bayburt-Everekhanları 6, Amasya Gümüşhacıköy 12 ve Ankara Kalecik 13 olmak üzere) ana ve iz element analizleri yaptırılmıştır. Sonuçlar Tablo 1'de sunulmuştur.

Kayaçların $\mathrm{SiO}_{2}$ içerikleri \%45 ila \%53 arasında değişmektedir. Genel olarak bakıldığında ALV'lerin $\mathrm{SiO}_{2}$ içerikleri (ortalama \%52) ABV'lere göre (ortalama \%48.5) biraz daha yüksektir (Tablo 1).

Bayburt'ta, ALV ortalama olarak yaklaşı $\% 53$ civarında $\mathrm{SiO}_{2}$ içerirken, $\mathrm{ABV}$ 'lerin $\quad \mathrm{SiO}_{2}$ içerikleri ortalama \%48'dir. Benzer şekilde Gümüşhacıköy ve Kalecikte bulunan ALV'ler yaklaşık \%52 $\mathrm{SiO}_{2}$ içerirken, bunlarla beraber bulunan $\mathrm{ABV}$ 'lerin ortalama $\mathrm{SiO}_{2}$ içerikleri sirasiyla $\% 50$ ile $\% 47$ 'dir. En yüksek ortalama $\mathrm{TiO}_{2}$ ve $\mathrm{P}_{2} \mathrm{O}_{5}$ değerleri Bayburt volkanitlerinde analiz edilmiştir (Tablo 1).

Bayburt'taki ALV'ler yaklaşık \%0.74 $\mathrm{TiO}_{2}$ ve $0.54 \mathrm{P}_{2} \mathrm{O}_{5}$ içerirken, eşlik eden volkanitlerin $\mathrm{TiO}_{2}$ ve $\mathrm{P}_{2} \mathrm{O}_{5}$ içerikleri ortalama $\% 0.95$ ve $\% 0.96$ 'dır. Gümüşhacıköy lokasyonunda ABV'ler ortalama $\% 0.90 \mathrm{TiO}_{2}$ ve \%0.50 $\mathrm{P}_{2} \mathrm{O}_{5}$ içerirken, ALV'ler ortalama \%0.64 $\quad \mathrm{TiO}_{2}$ ve $\% 0.52 \quad \mathrm{P}_{2} \mathrm{O}_{5}$ içerir. Ankara Kalecik'te bulunan volkanitlerin $\mathrm{TiO}_{2}$ ve $\mathrm{P}_{2} \mathrm{O}_{5}$ içerikleri diğer lokasyonlara göre biraz daha düşük olup, ABV'ler ortalama $\% 0.72 \mathrm{TiO}_{2}$ ve $\% 0.40 \mathrm{P}_{2} \mathrm{O}_{5}$, ALV'ler ise $\% 0.6 \mathrm{TiO}_{2}$ ve \%0.31 $\mathrm{P}_{2} \mathrm{O}_{5}$ içerir. ALV'ler ABV'lere göre daha fazla $\mathrm{Al}_{2} \mathrm{O}_{3}$ içerirler (Tablo 1).

Bayburt ALV'leri ortalama \%18.75, ABV'leri ise $\% 16.60 \mathrm{Al}_{2} \mathrm{O}_{3}$ içerir. Gümüşhacıköy örnekleri diğer lokasyonlara göre biraz daha az $\mathrm{Al}_{2} \mathrm{O}_{3}$ içeriğine sahiptir (ortalama \%15.40 ALV ve $\% 14.90 \mathrm{ABV})$. Kalecik'te ise ortalama $\mathrm{Al}_{2} \mathrm{O}_{3}$ içerikleri ortalamadan hesaplanan standart sapma limitleri içerisinde birbirlerine çok yakın değerlerdedir (\%16.0 ABV'de ve \% 16.4 ALV'de).
Genel olarak bakıldığında örneklerin $\mathrm{Mg} \# 0.44$ ila 0.58 arasında değişmektedir $(\mathrm{Mg \#}=(\mathrm{MgO} /$ $40.31) /\left((\mathrm{MgO} / 40.31)+\left(0.89 * \mathrm{Fe}_{2} \mathrm{O}_{3} / 71.89\right)\right)$ ve bu değerler söz konusu magmaların birincil magmalar (Mg\#: 0.63-0.73, Green, 1971) olmadığını gösterir. Söz konusu kayaçların içermiş olduğu düşük $\mathrm{Ni}$ (1.5 ila $54 \mathrm{ppm}$ ) ve $\mathrm{Cr}$ (\% 0.003 ila \% $0.027 \mathrm{Cr}_{2} \mathrm{O}_{3}$ ) içerikleri de bu savı desteklemektedir (Tablo 1).

$\mathrm{SiO}_{2}$ 'ye karşı toplam alkali diyagramında (Şekil 9) tüm örnekler Irvine ve Baragar'ın (1971) önerdiği alkali/yarı-alkali sınırın alkali kısmında yer almaktadır. Bayburt ABV örnekleri tefrit/fonotefrit alanına düşerken, ALV'i ise tefrifonolit alanında yer alır. Gümüşhacıköy ABV örnekleri trakibazalt/bazaltiktrakiandezit ve trakiandezit alanları boyunca sıralanmıştır. Aynı lokasyonun ALV'i tefrifonolit alanında yer alır. Benzer şekilde, Ankara Kalecik'ten derlenen $\mathrm{ABV}$ trakibazalt / tefrit ve fonotefrit alanlarında bulunurken, ALV'i ise fonotefrit / tefrifonolit / trakiandezit üçlüsünün oluşturduğu sınırda yer alır.

Winchester ve Floyd (1977) tarafindan önerilen ayrışmaya duyarlı iz elementlerden oluşturulmuş $\mathrm{Zr} / \mathrm{TiO} 2 * 0.0001$ 'a karş1 $\mathrm{Nb} / \mathrm{Y}$ diyagramında örnekler (Şekil 10), çoğunlukla subalkali/alkali geçiş alanında yer alır. Bunun nedeninin bu kayaçlarda beklenen yüksek $\mathrm{Nb}$ değerlerinin olmaması, yani bu kayaçların yitimle ilgili bir kaynaktan türemiş olmalarıdır.

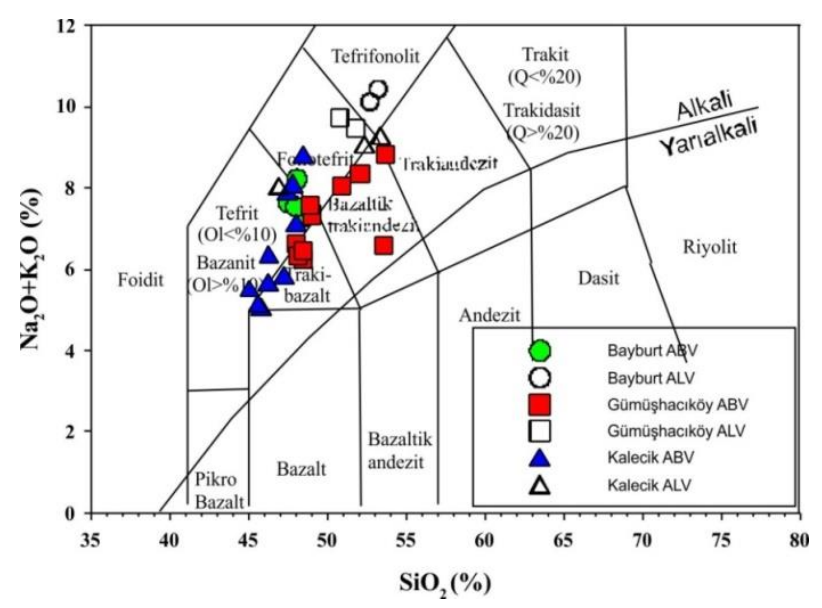

Şekil 9. Çalışma arazilerinden derlenerek analizi yapılan örneklerin toplam alkaliye karşı $\mathrm{SiO}_{2}$ diyagramındaki (Le Maitre vd., 2002) konumları (alkali-yarı alkali çizgisi Irving ve Baragar, 1971'den). 
Tablo 1. Çalışlan kayaçlara ait ana oksit (\%) ve iz (ppm) element değerleri ve bu değerlerden itibaren hesaplanmış normları (L-latit, T-tefrit-PT-fonotefrit).

\begin{tabular}{|c|c|c|c|c|c|c|c|c|c|c|c|c|c|c|c|}
\hline Lokasyon & Bayburt & Bayburt & Bayburt & Bayburt & Bayburt & Bayburt & $\begin{array}{l}\text { Gümüş- } \\
\text { hacıköy }\end{array}$ & $\begin{array}{l}\text { Gümüş- } \\
\text { hacıköy }\end{array}$ & $\begin{array}{l}\text { Gümüş- } \\
\text { hacıköy }\end{array}$ & $\begin{array}{l}\text { Gümüş- } \\
\text { hacıköy }\end{array}$ & $\begin{array}{l}\text { Gümüş- } \\
\text { hacıköy }\end{array}$ & $\begin{array}{l}\text { Gümüş- } \\
\text { hacıköy }\end{array}$ & $\begin{array}{l}\text { Gümüş- } \\
\text { hacıköy }\end{array}$ & $\begin{array}{l}\text { Gümüş- } \\
\text { hacıköy }\end{array}$ & $\begin{array}{l}\text { Gümüş- } \\
\text { hacıköy }\end{array}$ \\
\hline Örnek No & BB-1 & BB-2 & BB-3 & BB-5 & BB-4 & BB-6 & GB-1 & GB-2 & GB-3 & GB-4 & GH-1 & GH-2 & GH-3 & GH-5 & GH-6 \\
\hline Kayaç Tipi & $\mathrm{ABV}$ & $\mathrm{ABV}$ & $\mathrm{ABV}$ & $\mathrm{ABV}$ & ALV & ALV & $\mathrm{ABV}$ & $\mathrm{ABV}$ & $\mathrm{ABV}$ & $\mathrm{ABV}$ & $\mathrm{ABV}$ & $\mathrm{ABV}$ & $\mathrm{ABV}$ & $\mathrm{ABV}$ & $\mathrm{ABV}$ \\
\hline $\mathrm{SiO}_{2}$ & 48.5 & 47.5 & 48.05 & 47.97 & 52.7 & 53.2 & 48.99 & 53.57 & 48.42 & 48.93 & 48 & 48.12 & 52.07 & 53.72 & 50.86 \\
\hline $\mathrm{TiO}_{2}$ & 0.96 & 0.95 & 0.92 & 0.95 & 0.74 & 0.74 & 0.68 & 0.62 & 1.46 & 1.11 & 1.01 & 1.02 & 0.65 & 0.76 & 0.69 \\
\hline $\mathbf{A l}_{2} \mathrm{O}_{3}$ & 16.53 & 16.43 & 16.78 & 16.6 & 18.7 & 18.83 & 14.13 & 13.68 & 14.53 & 14.74 & 14.68 & 14.94 & 15.45 & 16.25 & 15.6 \\
\hline $\mathrm{Fe}_{2} \mathrm{O}_{3}$ & 10.3 & 10.1 & 10.87 & 10.2 & 6.8 & 6.71 & 7.14 & 6.78 & 11.84 & 10.73 & 10.4 & 10.53 & 7.1 & 8.21 & 8.35 \\
\hline MnO & 0.18 & 0.25 & 0.22 & 0.19 & 0.16 & 0.16 & 0.2 & 0.12 & 0.13 & 0.16 & 0.19 & 0.16 & 0.11 & 0.14 & 0.11 \\
\hline MgO & 5.46 & 5.53 & 5.69 & 5.5 & 3.93 & 4.11 & 5.12 & 4.29 & 5.61 & 4.85 & 5.5 & 5.6 & 4.82 & 3.16 & 5.12 \\
\hline $\mathrm{CaO}$ & 6.94 & 6.7 & 7.1 & 7.1 & 2.91 & 2.56 & 6.72 & 4.49 & 7.62 & 7.16 & 8.69 & 8.8 & 5.53 & 5.12 & 5.05 \\
\hline $\mathrm{Na}_{2} \mathrm{O}$ & 6.22 & 6.74 & 7.05 & 6.66 & 3.53 & 3.7 & 4.57 & 4.97 & 4.41 & 5 & 4.41 & 4.66 & 5.78 & 7.08 & 6.67 \\
\hline $\mathrm{K}_{2} \mathrm{O}$ & 1.07 & 0.89 & 1.17 & 0.88 & 6.59 & 6.74 & 2.77 & 1.63 & 1.83 & 2.59 & 2.24 & 1.68 & 2.58 & 1.75 & 1.39 \\
\hline $\mathrm{P}_{2} \mathrm{O5}$ & 0.99 & 0.99 & 0.85 & 0.99 & 0.54 & 0.54 & 0.4 & 0.46 & 0.51 & 0.55 & 0.53 & 0.53 & 0.5 & 0.52 & 0.53 \\
\hline A.K. & 2.5 & 3.8 & 1.85 & 2.5 & 3.8 & 2 & 8.5 & 8 & 4 & 4.5 & 3.8 & 3.5 & 4.4 & 3 & 4.7 \\
\hline Toplam & 99.65 & 99.88 & 100.55 & 99.54 & 100.4 & 99.29 & 99.22 & 98.61 & 100.36 & 100.32 & 99.45 & 99.54 & 98.99 & 99.71 & 99.07 \\
\hline Mg\# & 52.6 & 53.4 & 52.3 & 53.1 & 54.8 & 56.2 & 60.1 & 57 & 49.8 & 48.7 & 52.6 & 52.7 & 58.7 & 44.7 & 56.3 \\
\hline $\mathrm{K}_{2} \mathrm{O} / \mathrm{Na}_{2} \mathrm{O}$ & 0.172 & 0.132 & 0.166 & 0.132 & 1,867 & 1,822 & 0.606 & 0.328 & 0.415 & 0.518 & 0.508 & 0.361 & 0.446 & 0.247 & 0.208 \\
\hline kuv & & & & & & & & 5.64 & & & & & & & \\
\hline kor & & & & & 1.75 & 2.08 & & & & & & & & & \\
\hline or & 6.32 & 5.25 & 6.38 & 5.19 & 38.75 & 39.79 & 16.35 & 9.62 & 10.76 & 15.24 & 13.22 & 9.92 & 15.23 & 10.33 & 8.21 \\
\hline ab & 38.76 & 36.95 & 32.33 & 36.85 & 28.25 & 28.83 & 32.08 & 42.01 & 34.67 & 31.06 & 27.2 & 30.96 & 40.68 & 50.22 & 45.56 \\
\hline an & 13.4 & 11.95 & 10.63 & 12.81 & 10.89 & 9.2 & 9.86 & 10.21 & 14.35 & 10.1 & 13.65 & 14.18 & 8.6 & 7.4 & 8.53 \\
\hline ne & 7.49 & 10.85 & 14.6 & 10.54 & 0.8 & 1.33 & 3.55 & & 1.38 & 6 & 5.46 & 4.57 & 4.43 & 5.22 & 5.86 \\
\hline di & 11.4 & 11.6 & 14.76 & 12.48 & & & 16.29 & 7.09 & 15.61 & 16.97 & 20.3 & 19.89 & 12.16 & 11.41 & 10.21 \\
\hline ol & 5.84 & 5.9 & 5.1 & 5.56 & 6.84 & 7.19 & 3.66 & & 4.7 & 2.94 & 3.02 & 3.16 & 4.48 & 1.82 & 5.14 \\
\hline il & & 0.54 & 0.47 & 0.41 & 0.34 & 0.34 & 0.43 & 0.26 & 0.28 & 0.34 & 0.41 & 0.41 & 0.24 & 0.3 & 0.24 \\
\hline hem & & 10.12 & 10.83 & 10.12 & 6.79 & 6.72 & 7.15 & 6.79 & 11.82 & 10.72 & 10.42 & 10.2 & 7.11 & 8.23 & 8.37 \\
\hline ap & & 2.16 & 1.85 & 2.16 & 1.17 & 1.18 & 0.87 & 1 & 1.11 & 1.2 & 1.26 & 1.16 & 1.09 & 1.14 & 1.16 \\
\hline $\mathbf{Q}$ & & & & & & & & 0.08 & & & & & & & \\
\hline F & 0.1 & 0.14 & 0.18 & 0.14 & 0.01 & 0.02 & 0.05 & & 0.02 & 0.09 & 0.08 & 0.07 & 0.06 & 0.07 & 0.08 \\
\hline $\mathbf{A}$ & 0.19 & 0.21 & 0.27 & 0.21 & 0.5 & 0.51 & 0.3 & 0.14 & 0.19 & 0.31 & 0.29 & 0.23 & 0.27 & 0.84 & 0.81 \\
\hline $\mathbf{P}$ & 0.7 & 0.64 & 0.54 & 0.65 & 0.49 & 0.47 & 0.64 & 0.77 & 0.78 & 0.6 & 0.63 & 0.7 & 0.67 & 0.09 & 0.12 \\
\hline Kyç. Tipi & PT & PT & PT & PT & $\mathrm{T}$ & $\mathrm{T}$ & $\mathrm{L}$ & $\mathrm{L}$ & $\mathrm{L}$ & $\mathrm{L}$ & $\mathrm{L}$ & $\mathrm{L}$ & $\mathrm{L}$ & $\mathrm{T}$ & $\mathrm{T}$ \\
\hline $\mathbf{N i}$ & 23 & 25 & 13 & 18 & 28 & 32 & 47 & 54 & 43 & 35 & 15.8 & 15.7 & 33.8 & 10.5 & 39.2 \\
\hline Sc & & & & & & & & & & & 30 & 30 & 22 & 16 & 22 \\
\hline Ba & 1203 & 956 & 184 & 875 & 245 & 178 & 2040 & 1276 & 1170 & 972 & 1882 & 1172 & 1393 & 956 & 871 \\
\hline Co & & & & & & & & & & & 34.5 & 33.7 & 23 & 23.9 & 27.2 \\
\hline Cs & & & & & & & & & & & 4 & 7.1 & 3.3 & 4.3 & 2.5 \\
\hline Ga & & & & & & & & & & & 16.6 & 15.6 & 13.4 & 14.7 & 14.4 \\
\hline Hf & 3.58 & 2.72 & 3.97 & 4.23 & 4.32 & 4.28 & 3.27 & 3.3 & 4.17 & 3.34 & 3.1 & 3 & 2.9 & 3.7 & 3.3 \\
\hline Nb & 13.7 & 19.1 & 16.4 & 14.6 & 10.9 & 12 & 10 & 10 & 10 & 10 & 9.3 & 9.1 & 9.9 & 10.7 & 11.2 \\
\hline $\mathbf{R b}$ & 23 & 21 & 101 & 19 & 108 & 108 & 123 & 63 & 44 & 31 & 30.4 & 30.8 & 77.9 & 88 & 49.8 \\
\hline $\mathrm{Sr}$ & 856 & 405 & 841 & 791 & 792 & 776 & 630 & 585 & 653 & 355 & 736.2 & 665.1 & 494.6 & 504.6 & 389.6 \\
\hline Ta & 0.75 & 0.2 & 0.92 & 0.6 & 0.92 & 0.4 & 0.3 & 0.3 & 0.4 & 0.3 & 0.5 & 0.6 & 0.5 & 0.7 & 0.5 \\
\hline Th & 14.4 & 7 & 15.4 & 16.3 & 15.3 & 15.1 & 14 & 15 & 11 & 12 & 10.1 & 9.2 & 15.6 & 20.5 & 18 \\
\hline $\mathbf{U}$ & 4.1 & 1.6 & 5.8 & 2.6 & 3.9 & 4.8 & 2 & 3 & 2 & 2 & 2.7 & 1.9 & 6.3 & 2.6 & 9.2 \\
\hline V & 271 & - & 154 & - & - & - & & & & & 299 & 301 & 192 & 219 & 197 \\
\hline W & & & & & & & & & & & 0.6 & $<0.5$ & 1.7 & 0.9 & 1.6 \\
\hline $\mathbf{Z r}$ & 180 & 187 & 202 & 157 & 162 & 198 & 85 & 87 & 100 & 105 & 112.8 & 114.3 & 127.7 & 143.1 & 132.2 \\
\hline $\mathbf{Y}$ & 32.4 & 10.4 & 25.8 & 29 & 22.3 & 22.1 & 17 & 17 & 28 & 19 & 23.4 & 23.7 & 17.2 & 26.3 & 17.8 \\
\hline $\mathbf{L a}$ & 44.24 & 19.4 & 38.61 & 44.6 & 36.9 & 34.4 & 32.8 & 34.2 & 30.9 & 20.6 & 30.9 & 31.7 & 34.6 & 46.8 & 36 \\
\hline $\mathrm{Ce}$ & 87.75 & 39.2 & 72.49 & 104 & 81 & 77.3 & 66.7 & 67.7 & 68.3 & 45.9 & 61.1 & 63.3 & 65.6 & 88.5 & 67.8 \\
\hline Pr & & & & & & & & & & & 7.37 & 7.38 & 7.14 & 9.64 & 7.53 \\
\hline Nd & 46.5 & 15.21 & 33.86 & 49.46 & 34.8 & 32.28 & 28.05 & 28.02 & 34.1 & 20.04 & 29.6 & 29.8 & 27.8 & 38.1 & 28.5 \\
\hline Sm & 10.36 & 2.8 & 6.96 & 10.43 & 6.95 & 6.48 & 5.62 & 5.56 & 7.42 & 4.1 & 6.44 & 6.5 & 5.69 & 7.83 & 5.72 \\
\hline Eu & 2.61 & 0.97 & 1.91 & 2.69 & 1.96 & 1.83 & 1.75 & 1.66 & 2.18 & 0.96 & 1.79 & 1.77 & 1.49 & 2.09 & 1.56 \\
\hline Gd & & & & & & & & & & & 5.77 & 5.82 & 4.61 & 6.81 & 4.92 \\
\hline $\mathbf{T b}$ & 1.12 & 0.43 & 0.87 & 1.5 & 1.01 & 0.96 & 0.8 & 0.79 & 1.28 & 0.71 & 0.87 & 0.86 & 0.67 & 0.97 & 0.69 \\
\hline Dy & 5.45 & 2.07 & 4.08 & 6.38 & 4.54 & 4.38 & 3.67 & 3.65 & 6.04 & 3.62 & 4.71 & 4.69 & 3.42 & 4.97 & 3.53 \\
\hline Но & 1.09 & 0.37 & 0.83 & 1.11 & 0.83 & 0.83 & 0.63 & 0.64 & 1.13 & 0.72 & 0.87 & 0.86 & 0.63 & 0.89 & 0.65 \\
\hline Er & 2.79 & 1.2 & 2.24 & 3.18 & 2.53 & 2.52 & 1.85 & 1.9 & 3.28 & 2.32 & 2.44 & 2.33 & 1.66 & 2.47 & 1.82 \\
\hline $\operatorname{Tm}$ & 0.43 & 0.16 & 0.39 & 0.39 & 0.34 & 0.34 & 0.25 & 0.25 & 0.45 & 0.32 & 0.36 & 0.36 & 0.25 & 0.35 & 0.26 \\
\hline $\mathbf{Y b}$ & 2.19 & 1.15 & 1.39 & 2.48 & 2.2 & 2.13 & 1.56 & 1.59 & 2.73 & 2.12 & 2.26 & 2.27 & 1.6 & 2.24 & 1.67 \\
\hline Lu & 0.35 & 0.17 & 0.35 & 0.32 & 0.31 & 0.3 & 0.21 & 0.22 & 0.38 & 0.3 & 0.33 & 0.33 & 0.23 & 0.32 & 0.24 \\
\hline$\overline{\mathrm{Cu}}$ & 83 & & 53 & & & & & & & & 126.9 & 156.2 & 4207 & 117.8 & 4029.1 \\
\hline $\mathbf{P b}$ & 24 & & 22 & & & & & & & & 6.6 & 7 & 28.4 & 24.7 & 23.6 \\
\hline $\mathrm{Zn}$ & 71 & & 60 & & & & & & & & 98 & 72 & 170 & 92 & 137 \\
\hline
\end{tabular}


Tablo 1'in devamı

\begin{tabular}{|c|c|c|c|c|c|c|c|c|c|c|c|c|c|c|c|c|}
\hline Lokasyon & $\begin{array}{l}\text { Gümüş- } \\
\text { hacıköy }\end{array}$ & $\begin{array}{l}\text { Gümüş- } \\
\text { hacıköy }\end{array}$ & $\begin{array}{l}\text { Gümüş- } \\
\text { hacıköy }\end{array}$ & Kalec & Kalecik & Kalecik & Kalecik & Kale & Kale & Kale & Kale & Kalecik & Kalc & Kalecik & Kale & x Kale \\
\hline Örnek No & GH-7 & GH-8 & GH-9 & KH-1 & KH-2 & KH-3 & KH-4 & KH-5 & KH-6 & KH-8 & KH-11 & KH-12 & KH-7 & KH-9 & KH-13 & KH-14 \\
\hline Kayaç Tipi & $\mathrm{ABV}$ & ALV & ALV & $\mathrm{ABV}$ & $\mathrm{ABV}$ & $\mathrm{ABV}$ & $\mathrm{ABV}$ & $\mathrm{ABV}$ & $\mathrm{ABV}$ & $\mathrm{ABV}$ & $\mathrm{ABV}$ & $\mathrm{ABV}$ & ALV & ALV & $\mathrm{ABV}$ & ALV \\
\hline $\mathrm{SiO}_{2}$ & 48.48 & 51.78 & 50.74 & 47.96 & 46.18 & 47.23 & 48.46 & 47.47 & 47.83 & 45.8 & 45.58 & 45.03 & 52.33 & 53.39 & 46.26 & 46.94 \\
\hline $\mathrm{TiO}_{2}$ & 1.01 & 0.65 & 0.63 & 0.66 & 0.7 & 0.81 & 0.64 & 0.7 & 0.69 & 0.76 & 0.76 & 0.8 & 0.6 & 0.6 & 0.71 & 0.58 \\
\hline $\mathrm{Al}_{2} \mathbf{O}_{3}$ & 14.56 & 15.39 & 15.41 & 17.37 & 13.34 & 17.78 & 16.76 & 17.09 & 17.17 & 14.57 & 14.37 & 13.9 & 16.86 & 16.56 & 17.28 & 15.78 \\
\hline $\mathrm{Fe}_{2} \mathrm{O}_{3}$ & 10.2 & 7.87 & 7.57 & 9.25 & 10.88 & 10.3 & 8.9 & 9.66 & 9.57 & 10.62 & 10.57 & 11.06 & 7.38 & 7.43 & 9.73 & 8.49 \\
\hline MnO & 0.21 & 0.15 & 0.14 & 0.23 & 0.2 & 0.25 & 0.29 & 0.25 & 0.24 & 0.2 & 0.2 & 0.2 & 0.15 & 0.15 & 0.26 & 0.18 \\
\hline MgO & 5.83 & 5.08 & 4.77 & 3.72 & 6.82 & 3.8 & 3.8 & 3.95 & 3.98 & 5.56 & 5.61 & 6.08 & 3.12 & 3.24 & 4.75 & 3.7 \\
\hline $\mathrm{CaO}$ & 8.48 & 4.32 & 4.78 & 7.71 & 10.8 & 10.07 & 4.87 & 5.77 & 5.44 & 11.77 & 12.12 & 10.93 & 5.81 & 5.5 & 9.12 & 8.24 \\
\hline $\mathrm{Na}_{2} \mathrm{O}$ & 4.27 & 4.33 & 4.96 & 5.05 & 3.38 & 3.91 & 4.92 & 5.53 & 5.77 & 3.12 & 3.2 & 3.2 & 4.38 & 3.58 & 3.42 & 4.34 \\
\hline $\mathrm{K}_{2} \mathrm{O}$ & 2.17 & 5.15 & 4.76 & 2.1 & 2.29 & 1.95 & 3.91 & 2.4 & 2.35 & 1.96 & 1.97 & 2.32 & 4.7 & 5.71 & 2.96 & 3.72 \\
\hline $\mathbf{P}_{2} \mathrm{O}_{5}$ & 0.51 & 0.53 & 0.51 & 0.46 & 0.4 & 0.68 & 0.38 & 0.38 & 0.41 & 0.35 & 0.32 & 0.3 & 0.25 & 0.25 & 0.34 & 0.43 \\
\hline A.K. & 3.8 & 4.3 & 5.4 & 5 & 4.6 & 2.8 & 6.5 & 6.3 & 6.1 & 4.9 & 4.9 & 5.8 & 4 & 3.2 & 4.7 & 6.9 \\
\hline Toplam & 99.52 & 99.55 & 99.67 & 99.51 & 99.59 & 99.58 & 99.43 & 99.5 & 99.55 & 99.61 & 99.6 & 99.62 & 99.58 & 99.61 & 99.53 & 99.3 \\
\hline Mg\# & 54.5 & 57.5 & 56.9 & 45.8 & 56.8 & 43.6 & 47.2 & 46.2 & 46.6 & 52.3 & 52.7 & 53.5 & 47 & 47.8 & 50.6 & 47.8 \\
\hline $\mathrm{K}_{2} \mathrm{O} / \mathrm{Na}_{2} \mathrm{O}$ & 0.508 & 1,189 & 0.96 & 0.416 & 0.678 & 0.499 & 0.795 & 0.434 & 0.407 & 0.628 & 0.616 & 0.725 & 1,073 & 1,595 & 0.865 & 0.857 \\
\hline \multirow{2}{*}{\multicolumn{17}{|c|}{$\overline{\text { kuv }}$}} \\
\hline & & & & & & & & & & & & & & & \\
\hline or & 12.81 & 30.4 & 28.1 & 13.3 & 13.52 & 11.51 & 23.08 & 14.17 & 13.87 & 11.57 & 11.63 & 13.69 & 27.74 & 33.71 & 17.47 & 21.96 \\
\hline ab & 29.42 & 28.98 & 26.49 & 20.38 & 16.78 & 25.95 & 27.94 & 31.79 & 33.39 & 17.24 & 14.94 & 14.61 & 29.2 & 17.41 & 18.21 & 17.13 \\
\hline an & 14.15 & 7.35 & 5.73 & 14.26 & 14.46 & 25.2 & 12.1 & 14.72 & 14.01 & 19.96 & 19.02 & 16.71 & 12.46 & 12.35 & 23.05 & $\quad 12.59$ \\
\hline$n \in$ & 3.62 & 4.13 & 8.37 & 4.23 & 6.39 & 3.85 & 7.4 & 8.11 & 8.34 & 4.95 & 6.56 & 6.74 & 4.24 & 1.54 & 5.8 & 10.6 \\
\hline di & 19.19 & 8.3 & 11.45 & 28.17 & 28.56 & 15.87 & 7.48 & 8.92 & 8.04 & 27.93 & 30.19 & 27.74 & 11.49 & 10.46 & 15.58 & 19.89 \\
\hline ol & 3.96 & 6.18 & 4.62 & 2.61 & 2.65 & 1.49 & 4.21 & 4.01 & 4.35 & 0.65 & & 1.62 & 1.72 & 27 & 3.24 & 0.01 \\
\hline il & 0.45 & 0.32 & 0.3 & 0.42 & 0.43 & 0.54 & 0.62 & 0.54 & 0.51 & 0.43 & 0.43 & 0.43 & 32 & 32 & 0.56 & 0.39 \\
\hline hem & 10.22 & 7.88 & 7.58 & 10.75 & 10.9 & 10.32 & 8.92 & 9.68 & 9.59 & 10.62 & 10.59 & 11.08 & 39 & 7.44 & 9.75 & 8.51 \\
\hline ap & 1.11 & 1.16 & 1.11 & 0.86 & 0.87 & 1.48 & 0.83 & 0.83 & 0.9 & 0.76 & 0.7 & 0.66 & 0.55 & 0.55 & 0.74 & 0.94 \\
\hline \multicolumn{17}{|l|}{$\bar{Q}$} \\
\hline $\mathbf{F}$ & 0.06 & 0.06 & 0.11 & 0.07 & 0.11 & 0.05 & 0.09 & 0.11 & 0.11 & 0.08 & 0.11 & 0.2 & 0.05 & 0.02 & 0.08 & 0.15 \\
\hline A & 0.26 & 0.46 & 0.47 & 0.31 & 0.35 & 0.22 & 0.39 & 0.29 & 0.28 & 0.28 & 0.31 & 0.35 & 0.41 & 0.46 & 0.33 & 0.45 \\
\hline $\mathbf{P}$ & 0.68 & 0.48 & 0.42 & 0.61 & 0.54 & 0.73 & 0.51 & 0.6 & 0.61 & 0.63 & 0.58 & 0.54 & 0.53 & 0.52 & 0.59 & 0.41 \\
\hline Kyç. Tipi & $\mathrm{L}$ & $\mathrm{T}$ & $\mathrm{T}$ & $\mathrm{L}$ & PT & $\mathrm{L}$ & $\mathrm{L}$ & PT & PT & $\mathrm{L}$ & $\mathrm{T}$ & $\mathrm{T}$ & $\mathrm{L}$ & $\mathrm{L}$ & PT & PT \\
\hline $\mathrm{Ni}$ & 14.6 & 31.2 & 30.4 & 1.5 & 16.5 & 1,7 & 1,7 & 1,7 & 1,6 & 26,6 & 27,2 & 12,8 & 4,9 & 4,1 & 4,3 & \\
\hline Sc & 30 & 20 & 20 & 16 & 37 & 18 & 15 & 17 & 17 & 36 & 37 & 37 & 16 & 17 & 20 & 10 \\
\hline $\mathbf{B a}$ & 1339 & 1588 & 1132 & 1679 & 1446 & 1569 & 2885 & 1607 & 1551 & 994 & 1028 & 743 & 1570 & 1711 & 1871 & 3592 \\
\hline Co & 32.3 & 5.4 & 23.3 & 26 & 34.9 & 28,2 & 27,5 & 29,5 & 28,7 & 34,2 & 35,6 & 38,3 & 19,1 & 19,4 & 30 & 28,5 \\
\hline Cs & 3. & 2 & 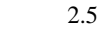 & 6 & 1.9 & 4 & 3, & 8,4 & 9 & 1,1 & 1,1 & 1,7 & 0,7 & 0,4 & 1,9 & 10,3 \\
\hline Ga & 15.4 & 14.7 & 14.1 & 16.6 & 13.3 & 15,9 & 12,6 & 15,7 & 15,2 & 13,3 & 14,3 & 14,4 & 5,3 & 14,6 & 15,6 & 14,8 \\
\hline Hf & 3 & 3.2 & 3.2 & 2.3 & 1.9 & 2,6 & 2,3 & 2,2 & 2,1 & 1,6 & 1,5 & 1,9 & 3 & 2,9 & 2,1 & 2,4 \\
\hline Nb & 8.7 & 9.7 & 9.9 & 10.5 & 5.8 & 15,7 & 8,2 & 8,6 & 9,2 & 4,1 & 4 & 5,6 & 8 & 7,9 & 7,1 & 18,4 \\
\hline 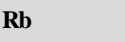 & 44.3 & 167.5 & 167.9 & 36.7 & 27.8 & 2 & 86 & 86,5 & 82,4 & 23,9 & 23 & 70,6 & 114,9 & 159,2 & 35,4 & 102,3 \\
\hline$S_{1}$ & 575.3 & 333.2 & 339.6 & 213.7 & 459.5 & 040,8 & 413,3 & 833,3 & 608 & 856,8 & 836,3 & 641,5 & 1035,9 & 1182,1 & 843,2 & 794 \\
\hline Ta & 0.5 & 0.6 & 0.5 & 0.5 & 0.2 & 0,7 & 0,4 & 0,4 & 0,4 & 0,2 & 0,2 & 0,2 & 0,4 & 0,5 & 0,3 & 0,7 \\
\hline Th & 9.3 & 15.4 & 15.2 & 18.5 & 8.5 & 13,9 & 13,6 & 15 & 15 & 6,1 & 5,7 & 7 & 14,8 & 14,4 & 14,4 & 20,9 \\
\hline U & 1. & 3.6 & 3 & 18 & 2 & 3,4 & 2,1 & 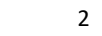 & 2,2 & $1, \varepsilon$ & 1,8 & 2,5 & 3,5 & 3,8 & 3 & 4,5 \\
\hline V & 27 & 14 & 133 & 2 & 332 & 301 & . & 307 & 298 & 310 & 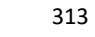 & 325 & 193 & 39 & 02 & 330 \\
\hline W & 0.9 & 2.1 & 1.8 & $<0.5$ & $<0.5$ & $<0.5$ & 1,2 & 1,3 & 1,6 & $<0.5$ & $<0.5$ & 1,6 & $<0.5$ & $<0.5$ & $<0.5$ & 0,6 \\
\hline $\mathrm{Zr}$ & 108.1 & 126.2 & 123.1 & 79.7 & 67.5 & 95.3 & 78.9 & 76.2 & 78.1 & 52.4 & 52.9 & 66.4 & 102.1 & 102.4 & 69.8 & 109.9 \\
\hline $\mathbf{Y}$ & 24 & 18.1 & 17.9 & 20 & 19.5 & 22.8 & 17.9 & 19.3 & 19.3 & 17.3 & 17.8 & 19.5 & 21.8 & 20.7 & 17.5 & 22.9 \\
\hline $\mathbf{L a}$ & & & & & 25.7 & 5 & 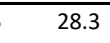 & 32 & 33.1 & 3 & 20.7 & 22.2 & 3.8 & 33.1 & 33.7 & 3.5 \\
\hline $\mathrm{Ce}$ & & & & & & & & 58 & 59 & & & 2.7 & 60.3 & & 60.3 & 2.1 \\
\hline Pr & & & & 7.4 & .02 & & 6.1 & 6.19 & 6.85 & 4.55 & 4.59 & 5.18 & 6.6 & 6.42 & 6.69 & .39 \\
\hline Nd & 28 & 27.7 & 26.7 & 29.2 & 24.1 & 35.3 & 24.4 & 26.7 & 27.4 & 17.5 & 18.6 & 22.1 & 24.9 & 24.5 & 25.9 & 3.2 \\
\hline Sm & 6. & 5.76 & 5.49 & 5.73 & 5.2 & 6.97 & 22 & 5.45 & 5.38 & 4.02 & 4.23 & 4.88 & 11 & 4.85 & 5.05 & 7.45 \\
\hline Eu & & 1.6 & 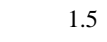 & 1 . & 1.5 & & & & 1.47 & 1 & 1.21 & 1.39 & 1.31 & 8 & 1.35 & $1.8 \mathrm{~s}$ \\
\hline Gd & & 4.76 & & & 4.75 & & & & 4.87 & 3.91 & 3.99 & 4.48 & 4.3 & 4.36 & 4.48 & 8 \\
\hline Tb & & 0.1 & & & & & & & 0.71 & 0.6 & 0.64 & 0.71 & 0.7 & 68 & 0.65 & 0.92 \\
\hline Dy & 4.63 & 3.51 & 3.36 & 3.87 & 3.92 & 4.37 & 3.46 & 3.73 & 3.74 & 3.41 & 3.4 & 3.93 & 3.79 & 65 & 3.43 & 1.72 \\
\hline Ho & 0.9 & 0.65 & 0. & 0.7 & 0.72 & 1 & 0.65 & 0.72 & 0.7 & 54 & 0.67 & 0.75 & 76 & 0.72 & 0.63 & 188 \\
\hline $\mathbf{E x}$ & & 1.8 & & 1.99 & & & & & 1.91 & 36 & 1.84 & 2.07 & 28 & 2.01 & 1.8 & 8 \\
\hline II & & 0.21 & & & & & & 0.28 & 0.28 & 0.26 & 0.26 & 0.3 & 36 & 31 & 0.26 & 34 \\
\hline Yl & 2. & 1.7 & 1.63 & & 1.79 & 3 & 1.65 & 1.77 & 1.77 & 1.7 & 1.68 & 1.86 & 25 & 2.12 & 1.6 & \\
\hline Lu & 0.32 & 0.25 & 0.23 & 0.27 & 0.26 & 0.31 & 0.24 & 0.26 & 0.25 & 0.24 & 0.26 & 0.29 & 0.35 & 0.31 & 0.23 & 0.29 \\
\hline $\mathbf{C u}$ & 91 & 118.3 & 65.5 & 164.7 & 168.2 & 112.4 & 185.1 & 156.7 & 191.1 & 118.4 & 117.1 & 116.6 & 123.8 & 134.6 & 189.7 & 483.3 \\
\hline 10 & 10.9 & 15.4 & 9.3 & 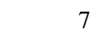 & 6.5 & 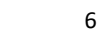 & 13.5 & 18.1 & 18.9 & 7.8 & 6.7 & 13.8 & 9.4 & 15.4 & 4.4 & 10.5 \\
\hline $\mathrm{Zn}$ & 63 & 234 & 44 & 72 & 76 & 81 & 84 & 76 & 79 & 72 & 71 & 63 & 90 & 58 & 83 & \\
\hline
\end{tabular}




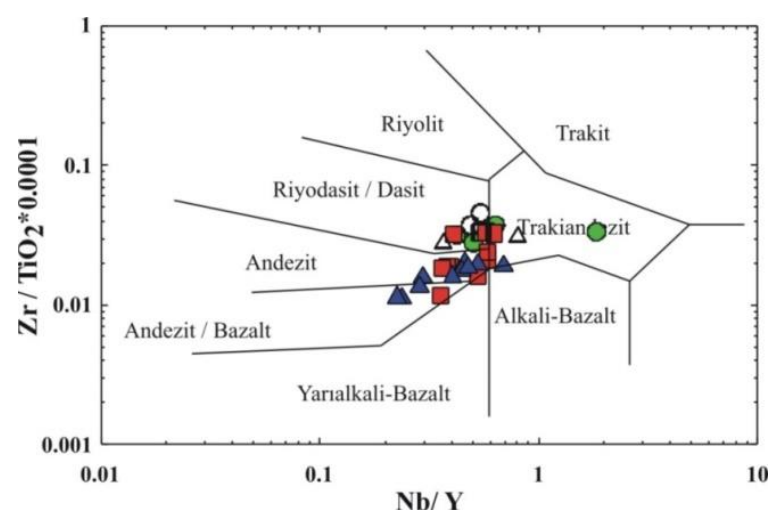

Şekil 10. Örneklerin ayrışmaya karşı duyarsız yüksek alana enerjili elementler kullanılarak hazırlanmış Winchester ve Floyd (1977) diyagramındaki konumları (semboller Şekil 9'daki gibidir).

Örneklerin ilksel mantoya (Sun ve McDonough, 1989) göre normalleştirilmiş iz element diyagramları irdelendiğinde (Şekil 11), genel hatlarıyla her üç lokasyondaki örneklerin (hem alkalen volkanitlerin hem de analsimli lösit içeren eşleniklerinin) çok benzer yönsemeler gösterdiği ortaya çıkmaktadır. Hemen hemen tüm örneklerin büyük iyon yarıçaplı element içerikleri, okyanus adas1 bazaltlarından (OIB) daha zengin olarak gözlenir. Tüm örneklerde $\mathrm{Nb}$-Ta negatif anomalisi belirgin iken, birçok örnekte de pozitif $\mathrm{Pb}$ ve negatif $\mathrm{Ti}$ anomalisi gözlenmektedir. Birçok örnekteki daha uyumlu yüksek alan enerjili element (Ti ve daha sağında bulunanlar) içerikleri, normal-okyanus ortası sirtı bazatları (N-MORB) ile benzer ve onlarla uyumludur. Bir birine paralel kondrit normalleştirilmiş (Boynton, 1984) lantan grubu element yönsemeleri hem lokasyonlar arasında hem de farklı kayaç tipleri için çok benzerdir. $\left([\mathrm{La} / \mathrm{Lu}]_{\mathrm{N}}\right.$ değerleri yaklaşı 10 , Şekil 12).
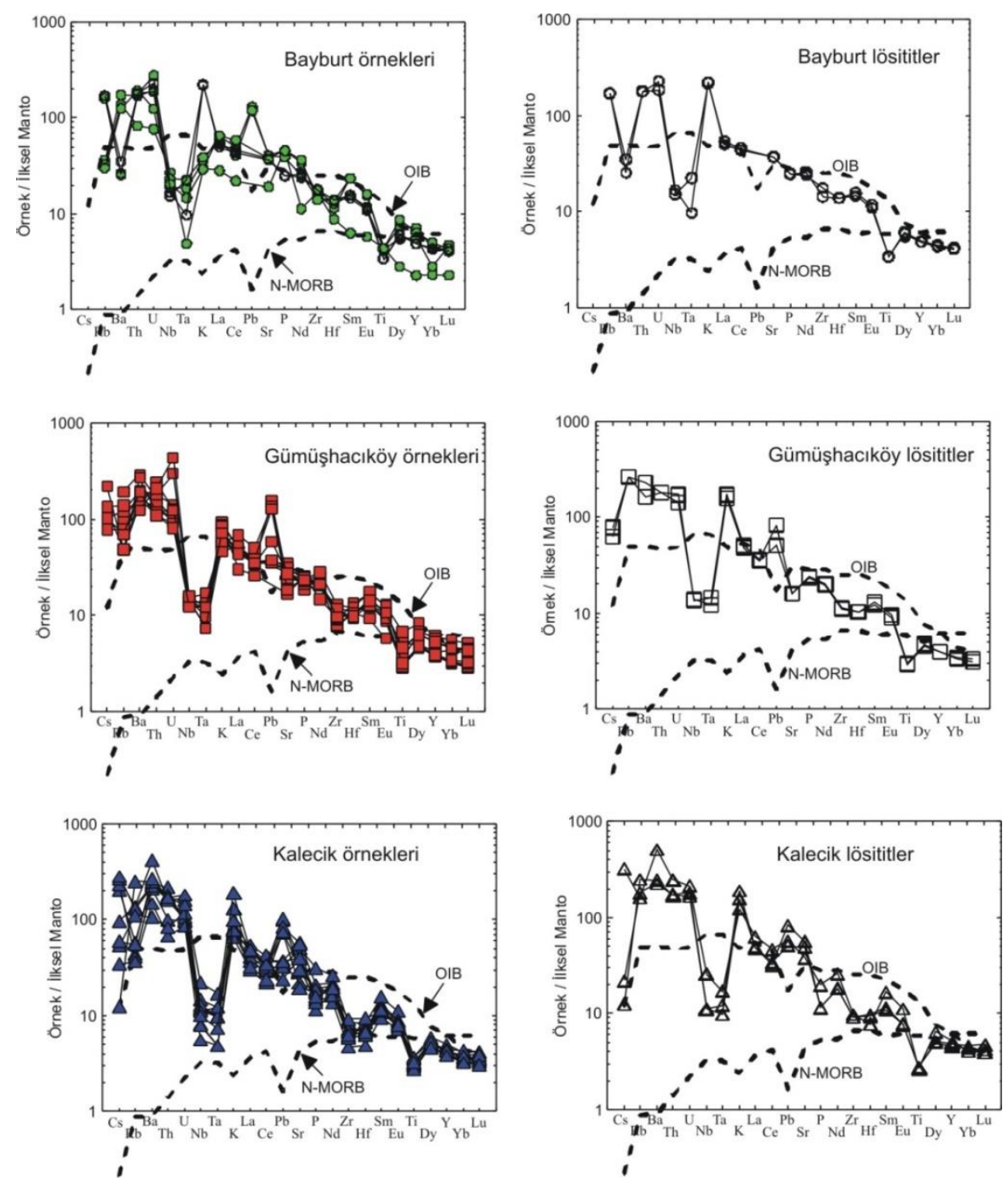

Şekil 11. Örneklerin ilksel mantoya göre normalleştirilmiş çoklu element dağılım diyagramları (normalleştirme değerleri, Okyanus Adası Bazatları (OIB) ve Normal Okyanus Ortası Sırtı Bazaltları (NMORB) değerleri Sun ve McDonough, 1989'dan alınmıştır. 

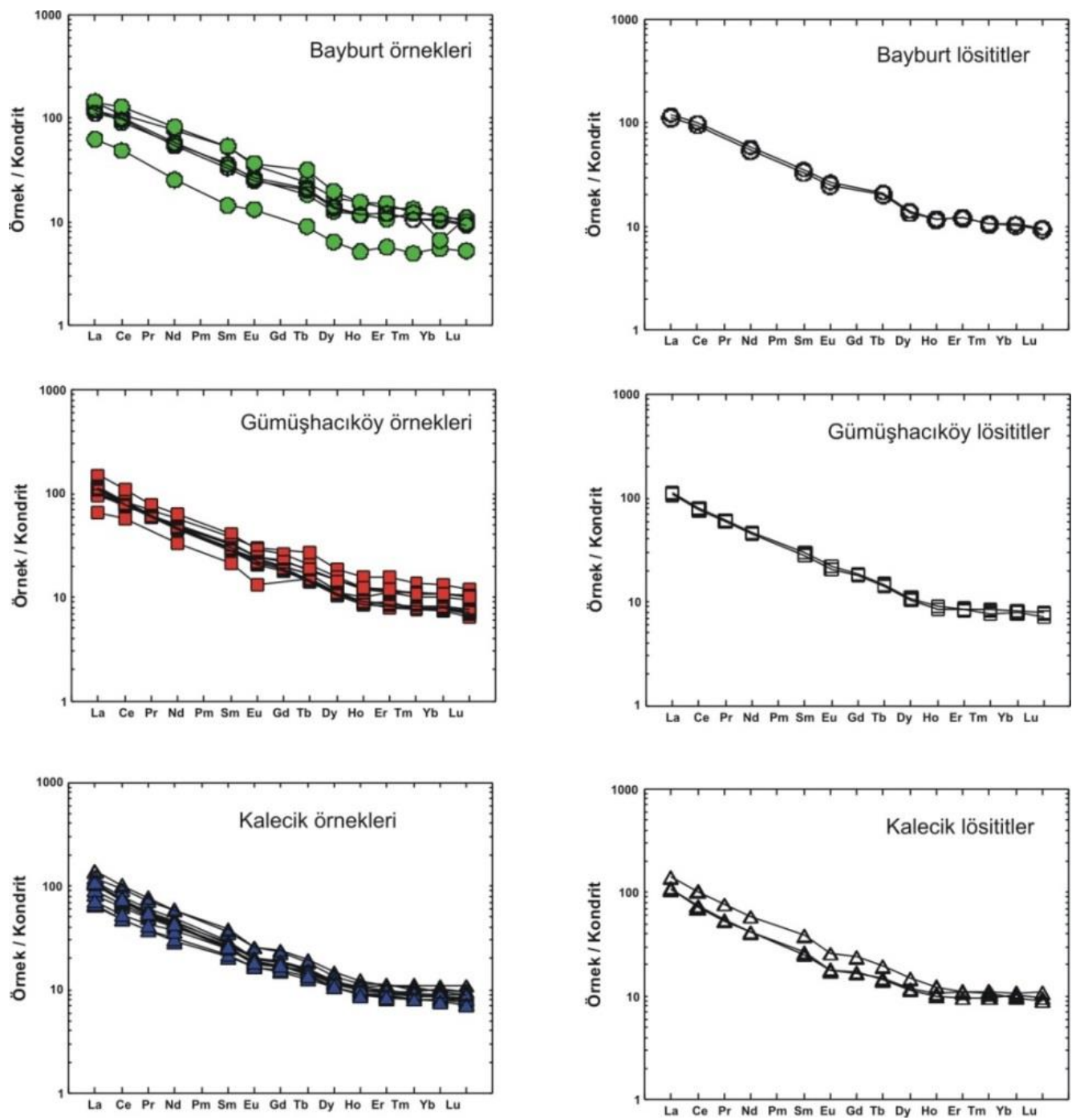

Şekil 12. Örneklerin lantanit grubu element analiz sonuçlarından kondrite göre normalleştirilmiş çoklu element dağılım diyagramları (kondrit değerleri Boynton, 1984'den alınmıştır).

\section{Tartışma}

\subsection{Volkanitlerin Jeotektonik Ortamı}

Sakarya zonunun güney kesimleri boyunca gözlenen alkalen volkanitlerin tektonik yerleşimleri de tartışmalıdır. Bundan dolayı öncelikle bu volkanitlerin tektonik yerleşim yerleri saptanmıștır. Müller vd. (1992), alkalen kayaçların kökensel ayrımı için ayrışmaya duyarlı yüksek alan enerjili elementleri kullanarak bir dizi ayırtman diyagram geliştirmiş̧tir. Söz konusu çalışmada, alkalen volkanitlerin oluşabileceği beş olası jeotektonik yerleşim alanı (i: kıtasal yay, ii: çarpışma sonrası yay, iii: başlangıç aşamasındaki okyanus yayı, iv: geç evre okyanus yayı ve v: plaka ortası volkanizması) tanımlanmıştır. İncelenen volkanitlerin adı geçen jeotektonik ortamlardan hangisine daha uygun olduğu Müller vd. (1992) tarafindan önerilen diyagramlarla test edilmiştir (Şekil 13). Yine bu çalışmada önerilen akış şemasına göre örneklerimiz sırasıyla $\mathrm{Zr} / \mathrm{Al}_{2} \mathrm{O}_{3}$ 'e karş1 $\mathrm{TiO}_{2} / \mathrm{Al}_{2} \mathrm{O}_{3} ; \mathrm{La}-\mathrm{TiO}_{2} / 100-\mathrm{Hf} * 10$, $\mathrm{Ce} / \mathrm{P}_{2} \mathrm{O}_{5}$ 'e karş1 $\mathrm{Zr} / \mathrm{TiO}_{2} ; \mathrm{Nb} * 50-\mathrm{Zr} * 3-\mathrm{Ce} / \mathrm{P}_{2} \mathrm{O}_{5}$ diyagramlarına düşürülmüştür. Tektonik ayırtman diyagramlarında örnekler yay-çarpışma sonrası yay alanlarında yer alır. Bu sonuç, Pontid'lerin Üst Kretase'deki jeotektonik evrimini güneyden kuzeye doğru yitim ve Eosen ve sonrasında çarpıșma teorisi ile açıklayan birçok çalıșmacının görüşü ile benzerdir (Okay ve Şahintürk, 1997; Okay vd., 1997; Boztuğ vd., 2006; Aydın vd. 2008; Aydınçakır ve Şen, 2013; Temizel vd., 2012; Yücel vd., 2017). Üst Kretase'nin sonunda yiten yaşlı levhanın dikleşmesi, yitim bileşenlerince zenginleşmiş manto kamasının derinlerinden kaynaklanan bölümsel ergime alanı oluştururken, çarpışma ile kapanan havzada biriken potasyumca zengin kırıntılılar bu ergiyiği alkalilerce zenginleştirmiştir (Şekil 14). Tüm lokasyonlarda aynı yerde ve benzer olarak bulunan ABV ile ALV arasındaki kökensel ilişki 
fraksiyonel kristallenme ile açıklanabilir. Şekil 15'da, $\mathrm{MgO}$ 'e karş1 $\mathrm{CaO} / \mathrm{Al}_{2} \mathrm{O}_{3}$ diyagramında bu volkanitlerin piroksen fraksiyonlaşmasının etkili olduğu görülmektedir. Piroksenlerin içerdiği $\mathrm{Ca}$,
$\mathrm{Mg}$ ve Fe'in alkali bazaltik ergiyikten ayrılması, ergiyikte ekstra alkali zenginleşmesine neden olup, lösitleri kristalleştirecek $\mathrm{K}$ aktivitesinin sağlanmasına neden olmuştur.
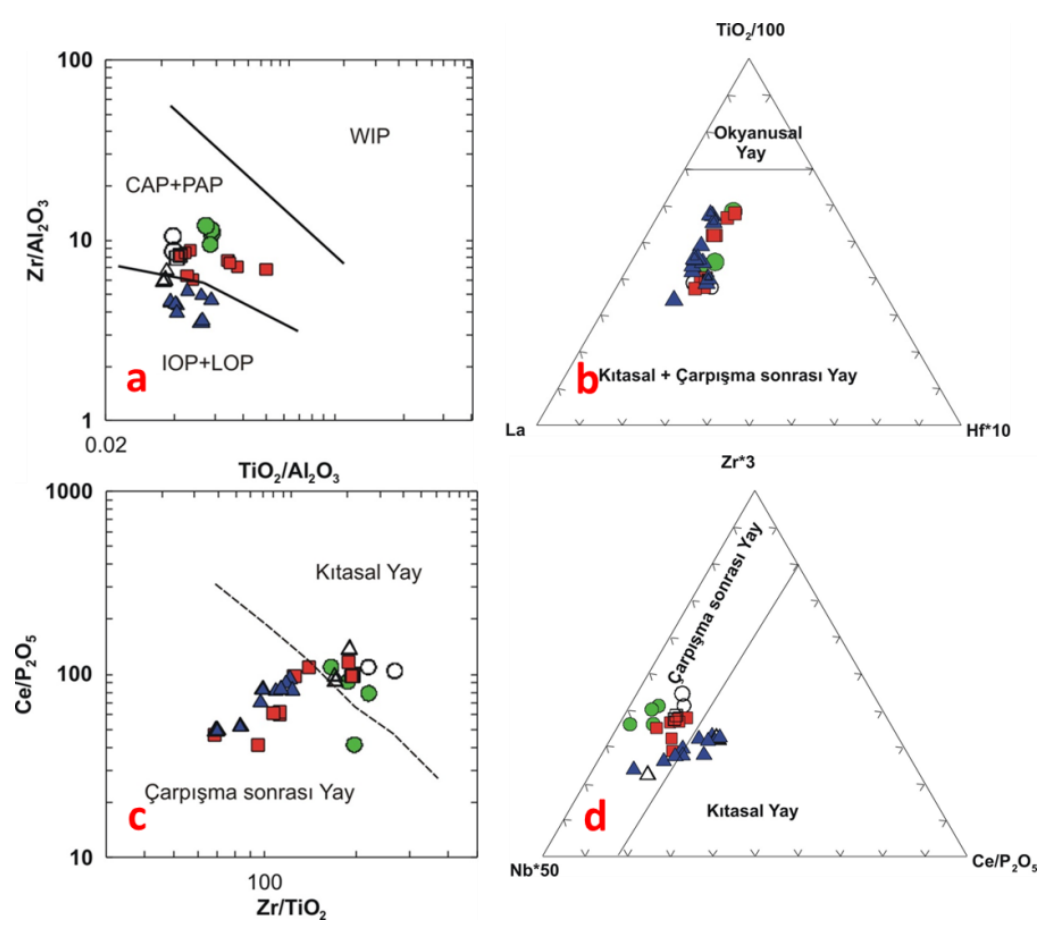

- Şekil 13. Alkalen kayaçların tektonik ortamını belirleyen diyagramlarda (Müller vd., 1992), çalışılan örneklerin konumları (Semboller Şekil 9'daki gibidir).

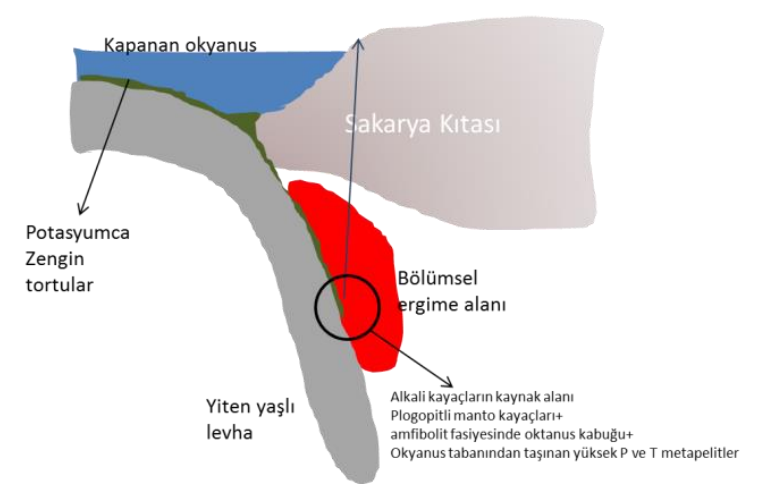

Şekil 14. ABV ve ALV'i oluşturan magmaların kökeninin şematik gösterimi.

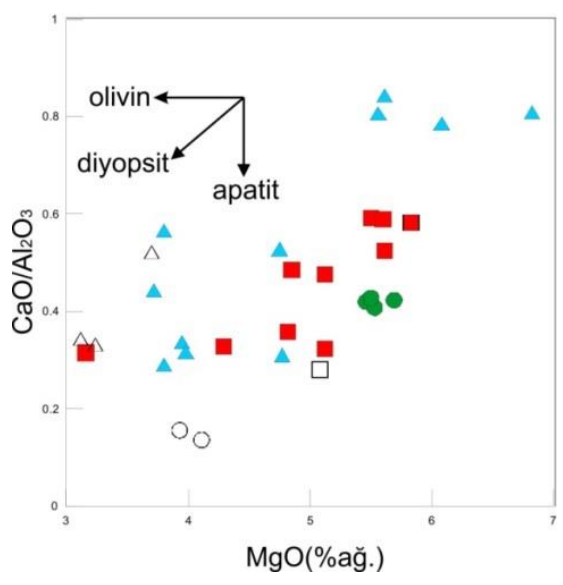

Şekil 15. İncelenen volkanitlerdeki MgO'e karşı $\mathrm{CaO} / \mathrm{Al}_{2} \mathrm{O}_{3}$ fraksiyonlaşma yönsemesi. 


\section{Sonuçlar}

Çalışılan volkanitler petrokimyasal olarak değerlendirildiğinde; Bayburt ABV örnekleri tefrit / fonotefrit, ALV'i ise tefrifonolit; Gümüşhacıköy ABV örnekleri trakibazalt/bazaltiktrakiandezit ve trakiandezit, ALV'i tefrifonolit; Ankara Kalecik'ten derlenen ABV trakibazalt / tefrit ve fonotefrit, ALV'i ise fonotefrit / tefrifonolit / trakiandezit bileşimde oldukları saptanmıştır.

Tektonik ayırtman diyagramlarına göre çalışılan volkanitler yay-çarpışma sonrası yay alanlarına düşmektedir. Alkalen volkanitlerini oluşturan magma Üst Kretase sonunda kuzeye doğru yitim yaparak kapanan bir yaşlı bir okyanus kabuğunun yitim açısının dikleşmesi ile oluşan manto kamasının derinlerinden kaynaklanmaktadır. ABV ile ALV arasındaki jenetik ilişki, piroksen fraksiyonlaşmasıyla karakterize olmuştur.

\section{Teşekkür}

$\mathrm{Bu}$ çalı̧̧ma Karadeniz Teknik Üniversitesi Bilimsel Araştırma Projeleri Birimi (Proje No: 1092) tarafından desteklenmiştir. Makalenin inceleme ve değerlendirme aşamasında yapmış oldukları katkılarından dolayı editör ve hakemlere teşekkür ederiz.

\section{Kaynaklar}

Alp, D., 1972. Amasya Yöresinin Jeolojisi. Doktora Tezi, İstanbul Teknik Üniversitesi, Fen Fakültesi Monografileri (Tabii İlimler k1sm1), İstanbul, 101s.

Altherr, R., Topuz, G., Siebel, W., Şen, C., Meyer, H. P., Satır, M. ve Lahaye, Y., 2008. Geochemical and $\mathrm{Sr}-\mathrm{Nd}-\mathrm{Pb}$ isotopic characteristics of Paleocene plagioleucitites from the Eastern Pontides (NE Turkey). Lithos, 105, 149-161.

Ataman, G., Buket, E. ve Çapan, U., 1976. Ankara Yöresinde Yer Alan Analsimli Magmatik Kayaçlar Hakkında Kısa Bir Not. Hacettepe Üniversitesi, Yerbilimleri Dergisi, 2, 3-5.

Aydın, F., Karsli, O. ve Chen, B., 2008. Petrogenesis of the Neogene alkaline volcanics with implcations for post collisional lithospheric thinning of the Eastern Pontides, NE Turkey. Lithos, 104, 249-266.
Aydınçakır, E. ve Şen, C., 2013. Petrogenesis of the post-collisional volcanic rocks from the Borçka (Artvin) area: implications for the evolution of the Eocene magmatism in the Eastern Pontides (NE Turkey). Lithos, 172173, 98-117.

Aydınçakır, E., 2016. Subduction-related Late Cretaceous high-K volcanism in the Central Pontides orogenic belt: Constraints on geodynamic implications. Geodinamica Acta, 28(4), 379-411.

Bektaş, O. ve Gedik, İ., 1988. Koplarda Lösitli Şoşonitik Volkanizmalı Yeni Bir Formasyon (Everekhanları Formasyonu) ve Bu Bulgunun Doğu Pontid Arkı (KD Türkiye) Evrimi ile Olan İlişkileri. Türkiye Jeoloji Bülteni, 31, 1120

Boynton, W. V., 1984. Cosmochemistry of the rare earth elements: Meteorite studies. Rare Earth Element Geochemistry. Henderson, P. (Ed.), Elsevier, Amsterdam. pp. 63-114.

Boztuğ, D., Erçin, A.İ., Kuruçelik, M.K., Göç, D., Kömür, İ. ve İskenderoğlu, A., 2006. Geochemical characteristics of the composite Kaçkar batholith generated in a Neo-Tethyan convergence system, Eastem Pontides, Turkey. Journal of Asian Earth Sciences, 27, 286-302.

Çapan, U., 1984. Ankara melanji içindeki zeolitli bazalt alkali volkanizmanın karakteri ve yaşı hakkında. TJK 38. Bilimsel ve Teknik Kurultay1, Bildiri Özleri Kitabı Bülteni, s. 121122.

Çoğulu, E. 1975. Gümüşhane ve Rize Bölgelerinde Petrografik ve Jeokronolojik Araştırmalar, ITUÜ Kütüphanesi, İstanbul, 1034 s.

Dokuz, A., 2011. A slab detachment and delamination model for the generation of Carboniferous high - potassium I-type magmatism in the Eastern Pontides, NE Turkey: The Köse composite pluton. Gondwana Research, 19, 926-944.

Dokuz, A., Aydınçakır, E., Kandemir, R., Karslı O., Siebel, W., Derman A.S. ve Turan, M., 2017b. Late Jurassic Magmatism and Stratigraphy in the Eastern Sakarya Zone, Turkey: Evidence for the Slab Breakoff of Paleotethyan Oceanic Lithosphere. The Journal of Geology, 125, 1-35. 
Dokuz, A., Külekçi, E., Aydınçakır, E., Kandemir, R., Alçiçek, M.C., Pecha, M. ve Sünnetçi, K., 2017a. Cordierite-bearing strongly peraluminous Cebre Rhyolite from theeastern Sakarya Zone, NE Turkey: Constraints on the Variscan Orogeny. Lithos, 278-281, 285-302.

Erk, A.S. ve Seymen, İ., 1993. Mecitözü Dolayının Stratigrafijk Gelişimi. Jeoloji Sempozyumu Bildirileri, Ankara, s. 129-141.

Eyüboğlu, 2010. Late Cretaceous high-K volcanism in the eastern Pontide orogenic belt: implications for the geodynamic evolution of NE Turkey. International Geology Review, 52, 142-186.

Eyüboğlu, Y., Santosh, M., Bektaş, O. ve Ayhan, S., 2011. Arc magmatism as a window to plate kinematics and subduction polarity: Example from the eastern Pontides belt, NE Turkey. Geoscience Fronteirs, 2(1), 49-56.

Fenerci, M., 1994, Rudists from Maden (Bayburt) area (NE Turkey). Turkish Journal of Earth Sciences, 3, 1-12.

Gülmez, F. ve Genç, Ş. C., 2015. Amasya civarı Geç Kretase yaşlı ultra potasik volkanitlerde farklılaşma süreçleri. Maden Tetkik ve Arama Enstitüsü Dergisi, 151, 153-172.

Gülmez, F., Genç, Ş. C., Preleviç, D. Tüysüz, O., Karacik, Z., Roden, M. ve Billor, Z., 2016. Ultrapotassic Volcanism from the Waning Stage of the Neotethyan Subduction: a Key Study from the Izmir-Ankara-Erzincan Suture Belt, Central Northern Turkey. Journal of Petrology, 57, 561-593.

Irvine, T. N. ve Baragar, W. R. A., 1971. A Guide to the Chermical Classification. Journal of Earth Sciences, 8, 523-546.

Kandemir, R. 2004. Gümüşhane yakın yörelerindeki Erken-Orta Jura Yaşlı Şenköy Formasyonu'nun Çökel Özellikleri ve Birikim Koşulları. Doktora Tezi, Karadeniz Teknik Üniversitesi Fen Bilimleri Enstitüsü, Trabzon.

Kandemir, R. ve Yilmaz, C. 2009. Lithostratigraphy, facies, and deposition environment of the lower Jurassic Ammonitico Rosso type sediments (ARTS) in the Gümüşhane area, NE Turkey: implications for the opening of the northern branch of the Neo-
Tethys Ocean. Journal of Asian Earth Science. 34, 586-598.

Karsl1, O., Dokuz, A. ve Kandemir, R., 2016. Subduction-related Late Carboniferous to Early Permian Magmatism in the Eastern Pontides, the Camlik and Casurluk plutons: insights from geochemistry, whole-rock $\mathrm{Sr}-\mathrm{Nd}$ and in situ zircon Lu-Hf isotopes, and $\mathrm{U}-\mathrm{Pb}$ geochronology.Lithos,266-267,98-114.

Karsl1, O., Dokuz, A. ve Kandemir, R., 2017. Zircon Lu-Hf isotope systematics and $\mathrm{U}-\mathrm{Pb}$ geochronology, whole-rock $\mathrm{Sr}-\mathrm{Nd}$ isotopes and geochemistry of the early Jurassic Gokcedere pluton, Sakarya Zone-NE Turkey: a magmatic response to roll-back of the Paleo-Tethyan oceanic lithosphere. Contributions to Mineralogy and Petrology, 172(5), 1-27.

Kaygusuz, A. ve Aydınçakır, E., 2011. U-Pb zircon SHRIMP ages, geochemical and Sr-Nd isotopic compositions of Cretaceous plutons in the eastern Pontides (NE Turkey): The Dağbaş1 pluton. Neues Jahrbuch Für Mineralogie, 188(3), 211-233.

Kaygusuz, A., Arslan, M., Siebel W. ve Şen, C., 2011. Geochemical and $\mathrm{Sr}-\mathrm{Nd}$ Isotopic Characteristics of Post-Collision Calc-Alkaline Volcanics in the Eastern Pontides (NE Turkey). Turkish Journal of Earth Sciences, 20, 137-159.

Kaygusuz, A., Arslan, M., Sipahi, F. ve Temizel, İ., 2016. U-Pb zircon chronology and petrogenesis of Carboniferous plutons in the northern part of the Eastern Pontides, NE Turkey: Constraints for Paleozoic magmatism and geodynamic evolution. Gondwana Research, 39, 327-346.

Kaygusuz, A., Arslan, M., Wolfgang, S., Sipahi, F. ve İlbeyli, N., 2012. Geochronological evidence and tectonic significance of Carboniferous magmatism in the southwest Trabzon area, Eastern Pontides, Turkey. International Geology Rewieve, 54 (15), 17761800.

Le Maitre, R. W., Streckeisen, A., Zanettin, B., Le Bas, M. J., Bonin, B., Bateman, P., Bellieni, G., Dudek, A., Efremova, S., Keller, J,. Lamere, J, Sabine, P. A., Schmid, R.,. Sorensen, H. ve Woolley A. R., 2002. Igneous Rocks: A Classification and Glossary of Terms, Recommendations of the International Union of Geological Sciences, Subcommission 
of the Syste-matics of Igneous Rocks. Cambridge University Press.

Müller, D., Rock, N.M.S. ve Groves, D.I., 1992. Geochemical Discrimination Between Shoshonitic and Potassic Volcanic Rocks in Different Tectonic Settings: a Pilot Study. Mineralogy and Petrology, 46, 259-289.

Okay, A. I. ve Şahintürk, O., 1997. Geology of the eastern pontides, in: Robinson, A.G. (Ed), Regional and petroleum geology of the Black Sea and surrounding region. American Association of Petroleum Geologists Memoir. 68, 291-311.

Okay, A. ve Tüysüz O., 1999. Tethyan sutures of northern Turkey. Geological Society, London, Special Publications.156, 475-515.

Okay, A.İ., Şahintürk, Ö. ve Akar, H., 1997. Stratigraphy and tectonics of the Pulur (Bayburt) region in the Eastern Pontides. Bulletin of the Mineral Research and Exploration, 119, 1-24.

Özer, S. ve Fenerci, M., 1993, Bayburt yöresinde (Doğu Karadeniz) bulunan iki yeni Caprinidae türü. MTA Dergisi, 115, 29-34.

Seymen, İ., 1975, Kelkit Vadisi Kesiminde Kuzey Anadolu Fay Zonunun Tektonik Özelliği. Doktora Tezi, İTÜ Maden Fakültesi. İstanbul.

Sun, S. ve McDonough, W. F., 1989. Chemical and isotopic systematics of oceanic basalts: Implications for mantle composition and processes. Geological Soceity of London, Special Publications, 42, 313-345.

Şen, C. 2007. Jurassic Volcanism in the Eastern Pontides:Is it Rift Related or Subduction Related? Turkish Journal of Earth Sciences, $16,523-539$.

Şengör, A. M. C. ve Yilmaz, Y. 1981. Tethyan Evolution of Turkey: A plate tectonic Approach. Tectonophysics, 75, 181-241.

Temizel, İ., Arslan, M., Ruffet, G. ve Peucat, J.J., 2012, Petrochemistry, geochronology and Sr$\mathrm{Nd}$ isotopic systematics of the Tertiary collisional and post-collisional volcanic rocks from the Ulubey (Ordu) area, eastern Pontide, NE Turkey: Implications for extension-related origin and mantle source characteristics. Lithos, 128, 126-147.

Topuz, G., Altherrr, R., Siebel, W., Schwarz, H. W., Zack, H., Hasöbek, A., Barth, M., Satır M. ve Șen C., 2010. Carboniferous high-potassium I-type granitoid magmatism in the EasternPontides: The Gümüşhane pluton (NE Turkey). Lithos, 116, 92-110.

Tüysüz, O., 1996. Geology of Amasya and surroundings, $11^{\text {th }}$ International Petroleum Congress and Exhibition of Turkey, Turkish Association of Petroleum Geologists, Ankara, Turkey, p. 32-48.

Üşenmez, Ş., 1973. Çandır (Kalecik) Civarının Jeolojisi. Maden Tetkik ve Arama Enstitüsü Dergisi, 83, 30-46.

Winchester, J. A. ve Floyd, P. A., 1977. Geochemical discrimination of different magma series and their differentiation products using immobile elements. Chemical Geology, 20, 325-343.

Yılmaz, C. ve Kandemir, R., 2003. Şenköy Formasyonu: Yeni bir formasyon adlamas1. 3. Stratigrafi Çalıştayı, Bildiri Özleri Kitabı, s14.

Y1lmaz, C., 2002. Gümüşhane-Bayburt yöresindeki mesozoyik havzalarının tektono sedimantolojik kayitları ve kontrol etkenleri, Türkiye Jeoloji Bülteni. 45 (1), 141-165.

Yılmaz, C., Şen, C. ve Özgür, S., 2003, Sedimentological, palaeontological and volcanic records of the earliest volcanic activity in the Eastern Pontide Cretaceous volcanic arc (NE Turkey). Geol. Carp., 54, 377-384.

Y1lmaz, Y. 1973. Petrology and structure of the Gümüşhane granite and the surrounding rocks, N.E. Anatolia. Ph. D. Thesis, University College London, England, 284 p.

Yücel, C., Arslan, M., Temizel, İ., Abdioğlu Yazar, E. ve Ruffet, G., 2017. Evolution of Krich magmas derived froma net veined lithospheric mantle in an ongoing extensional setting: geochronology and geochemistry of Eocene and Miocene volcanic rocks from Eastern Pontides (Turkey). Gondwana Research, 45, 65-86. 